\title{
Unraveling the Complex Delithiation Mechanisms of Olivine-Type Cathode Materials, $\mathrm{LiFe}_{x} \mathrm{Co}_{1-x} \mathrm{PO}_{4}$
}

Fiona C. Strobridge, ${ }^{\dagger}$ Hao Liu, ${ }^{\dagger, \|}$ Michal Leskes, ${ }^{\dagger, \perp}$ Olaf J. Borkiewicz, ${ }^{\ddagger}$ Kamila M. Wiaderek, ${ }^{\ddagger}$ Peter J. Chupas, ${ }^{\ddagger}$ Karena W. Chapman, ${ }^{\ddagger}$ and Clare P. Grey* ${ }^{* \dagger, \S}$

${ }^{\dagger}$ Department of Chemistry, University of Cambridge, Lensfield Road, Cambridge, Cambridgeshire CB2 1EW, U.K.

${ }^{\ddagger}$ X-ray Science Division, Advanced Photon Source, Argonne National Laboratory, Argonne, Illinois 60439, United States

${ }^{\S}$ Department of Chemistry, State University of New York at Stony Brook, Stony Brook, New York 11794-3400, United States

\section{Supporting Information}

\begin{abstract}
The delithiation mechanisms occurring within the olivine-type class of cathode materials for Li-ion batteries have received considerable attention because of the good capacity retention at high rates for $\mathrm{LiFePO}_{4}$. A comprehensive mechanistic study of the (de)lithiation reactions that occur when the substituted olivine-type cathode materials $\mathrm{LiFe}_{x} \mathrm{Co}_{1-x} \mathrm{PO}_{4}(x=0,0.05,0.125,0.25,0.5,0.75,0.875,0.95,1)$ are electrochemically cycled is reported here using in situ X-ray diffraction (XRD) data and supporting ex situ ${ }^{31} \mathrm{P}$ NMR spectra. On the first charge, two intermediate phases are observed and identified: $\mathrm{Li}_{1-x}\left(\mathrm{Fe}^{3+}\right)_{x}\left(\mathrm{Co}^{2+}\right)_{1-x} \mathrm{PO}_{4}$ for $0<x<1$ (i.e., after oxidation of $\mathrm{Fe}^{2+}$ to $\left.\mathrm{Fe}^{3+}\right)$ and $\mathrm{Li}_{2 / 3} \mathrm{Fe}_{x} \mathrm{Co}_{1-x} \mathrm{PO}_{4}$ for $0 \leq x \leq 0.5$ (i.e., the Co-majority materials). For the Fe-rich materials, we study how nonequilibrium, single-phase mechanisms that occur discretely in single particles, as observed for $\mathrm{LiFePO}_{4}$ at high rates, are affected by Co substitution. In the Co-majority materials, a two-phase mechanism with a coherent interface is observed, as was seen in $\mathrm{LiCoPO}_{4}$, and we discuss how it is manifested in the XRD patterns. We then compare the nonequilibrium, single-phase mechanism with the bulk single-phase and coherent interface two-phase mechanisms. Despite the apparent differences between these mechanisms, we discuss how they are related and interconverted as a function of $\mathrm{Fe} / \mathrm{Co}$ substitution and the potential implications for the electrochemistry of this system.
\end{abstract}

\section{INTRODUCTION}

Since the initial publication by Padhi et al. in 1997 on $\mathrm{LiFePO}_{4}{ }^{1}$ the olivine family has been extensively researched as potential cathode materials for Li-ion batteries. $\mathrm{LiFePO}_{4}$ 's high stability, long cycle life, good reversibility, ${ }^{2}$ and safe operating voltage (3.45 $\mathrm{V} \mathrm{vs}^{+} / \mathrm{Li}$ ) have led to its use in commercial batteries. While $\mathrm{LiFePO}_{4}$ has been widely studied, the mechanism by which it is transformed during electrochemical cycling is not trivial. The transformation mechanisms for the substituted and in principle higher-energy density variants $\mathrm{LiFe}_{x} \mathrm{M}_{1-x} \mathrm{PO}_{4}(\mathrm{M}=\mathrm{Mn}, \mathrm{Co}, \mathrm{Ni}$; $0 \leq x \leq 1)$ are even more complex and generally not well understood. Understanding how $\mathrm{Li}$ is deintercalated and reintercalated upon charging and discharging, respectively, is fundamental to explaining the electrochemical properties of known electrode materials and essential to help develop new electrode materials. Specifically, substitution of $\mathrm{Mn}, \mathrm{Co}$, and $\mathrm{Ni}$ generally results in poorer performance in terms of rate and capacity, but this is not true of all levels of metal substitution. It is therefore important to understand why some compositions show improved performance and others do not.

Here we use time-resolved in situ synchrotron X-ray diffraction methods to explore systematically how Co substitution in $\mathrm{LiFePO}_{4}$ alters the structural transformations that occur upon cycling for the entire $\mathrm{LiFe}_{x} \mathrm{Co}_{1-x} \mathrm{PO}_{4}$ phase diagram. We start by describing the possible relevant (de)lithiation mechanisms proposed for $\mathrm{LiFe}_{x} \mathrm{M}_{1-x} \mathrm{PO}_{4}$ and how they are, or would be, manifested in the $\mathrm{X}$-ray diffraction (XRD) data (Figure 1) in order to help in the interpretation of the in situ XRD data for the $\mathrm{LiFe}_{x} \mathrm{Co}_{1-x} \mathrm{PO}_{4}$ series presented in this paper.

Initially, XRD and transmission electron microscopy (TEM) studies carried out on micron-sized $\mathrm{LiFePO}_{4}$ particles identified a two-phase reaction mechanism (A) (illustrated in Figure 1) in which both end-member phases $\left(\mathrm{LiFePO}_{4}\right.$ and $\left.\mathrm{FePO}_{4}\right)$ are present, separated by a coherent interface within a single particle, at intermediate states of charge. ${ }^{1,3}$ This mechanism is observed as the simultaneous disappearance and growth of the XRD reflections of the reactant and product phases, respectively. Although micron-sized particles can be chemically delithiated, their electrochemical performance is poor. $\mathrm{LiFePO}_{4}$ (space group Pnma) has one-dimensional Li diffusion channels in the $b$ direction, ${ }^{4}$ and its electrochemical performance was found to significantly improve when the particles were nanosized. ${ }^{5}$ The decrease in particle size also leads to a change in the reaction mechanism since the high-energy interface between $\mathrm{LiFePO}_{4}$ and $\mathrm{FePO}_{4}$ is no longer stable within a single nanoparticle and only fully lithiated and fully delithiated particles could be detected in ex situ XRD studies upon cycling. ${ }^{6}$ These findings were explained by Delmas et al. ${ }^{6}$ in their domino-cascade model (B), in which the reaction occurs particle-by-particle (as shown in Figure 1), resulting in sequential, heterogeneous delithiation

Received: January 24, 2016

Revised: April 24, 2016

Published: April 25, 2016 


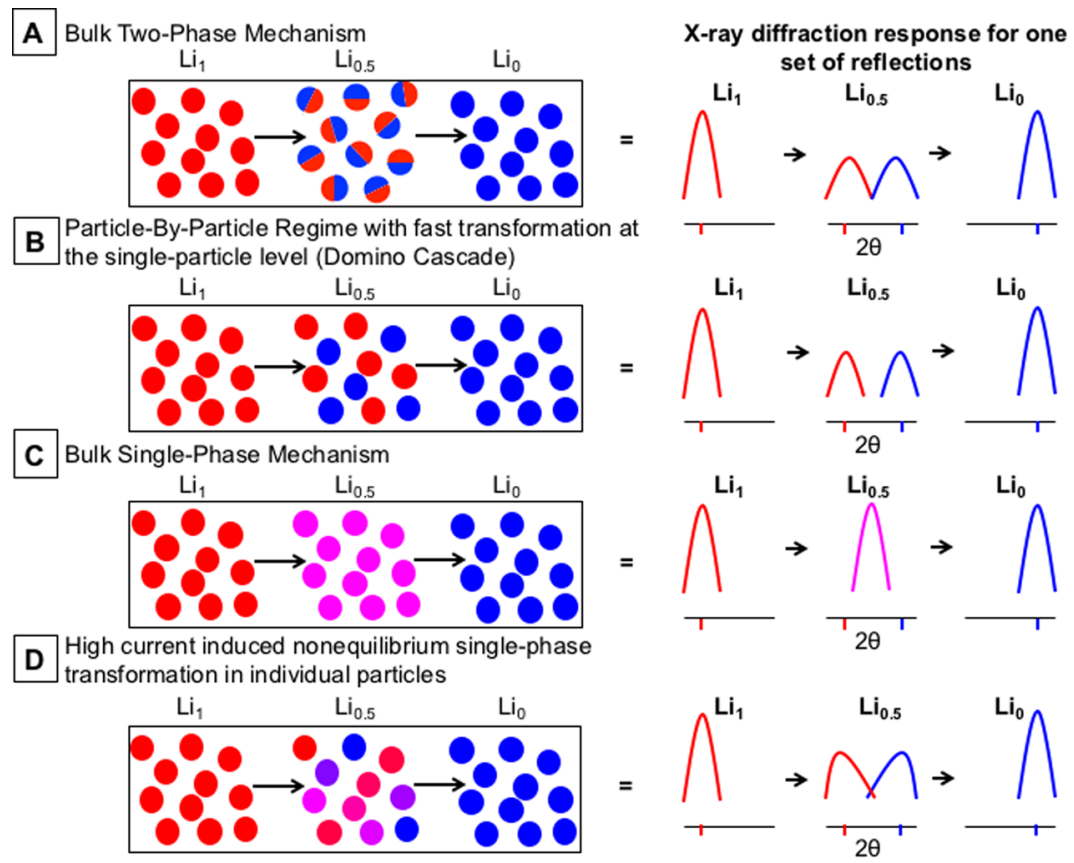

Figure 1. Simplified illustration of five different possible delithiation schemes for the olivine materials and their resulting in situ XRD responses for a single reflection (such as the 020 reflection) at the compositions $\mathrm{Li}_{1}, \mathrm{Li}_{0.5}$, and $\mathrm{Li}_{0}$ (i.e., $\mathrm{LiMPO}_{4}, \mathrm{Li}_{0.5} \mathrm{MPO}_{4}$ and $\mathrm{MPO}$ ): (A) the bulk two-phase mechanism in which both phases coexist in a single particle; $(\mathbf{B})$ the particle-by-particle reaction regime, where the particles exist only as either $\mathrm{Li}_{1}$ or $\mathrm{Li}_{0}{ }_{3}$ (C) the bulk single-phase mechanism; (D) the nonequilibrium single-phase transformation occurring sequentially particle-by-particle; (E) the two-phase mechanism with a coherent interface, explored in more detail in this paper.

of the particles in the electrode. It was proposed that the particles still undergo a two-phase mechanism, but since the interface is energetically unfavorable, it propagates very quickly within each particle. It should be noted that as a result of the added strain at the phase boundary that exists during reaction scheme $\mathbf{A}$, the full widths at half-maximum of specific classes of reflections in the diffraction experiment are expected to be larger than if the two phases exist in different particles, such as in scheme $\mathbf{B}$ (as illustrated in Figure 1). Recent soft X-ray ptychography combined with X-ray absorption spectroscopy and TEM measurements have shown that $\mathrm{LiFePO}_{4}$ and $\mathrm{FePO}_{4}$ can coexist in particles as small as $100 \mathrm{~nm}$.

The good capacity retention at exceptionally high rates for $\mathrm{LiFePO}_{4}$ nanoparticles ${ }^{8}$ is in apparent contradiction with a two-phase mechanism: two-phase mechanisms typically result in high activation energy barriers for the nucleation and growth of a new phase. Although the $\mathrm{Li}$ solubility in $\mathrm{Li}_{\delta} \mathrm{FePO}_{4}$ and $\mathrm{Li}_{1-\delta} \mathrm{FePO}_{4}$ increases as the particle size decreases, there is a still a miscibility gap even for $34 \mathrm{~nm}$ particles. ${ }^{9}$ Density functional theory calculations by Malik et al. ${ }^{10}$ predicted that a single-phase transformation is accessible when an overpotential is applied to nanosized $\mathrm{LiFePO}_{4}$. Ferguson and Bazant ${ }^{11}$ proposed, on the basis of their simulations, that metastable solid-solution phases arise from kinetic suppression of the phase separation. These proposals are supported by our in situ XRD studies ${ }^{12}$ and those of Zhang et al., ${ }^{13}$ which captured metastable structures extending across the whole $\mathrm{Li}_{y} \mathrm{FePO}_{4}$ composition range $(0 \leq y \leq 1)$ at high cycling rates. The metastable structures were observed as an asymmetric broadening of the Bragg reflections of the end-member phases toward each other (scheme $\mathbf{D}$ in Figure 1), resulting in the reflections forming one continuous peak. Our simulations of the diffraction data showed that this asymmetric broadening could not be modeled within a simple coherent interface model (scheme $\mathbf{E}) .{ }^{12,14}$ In practice it is difficult to determine whether some of the broadening originates from the existence of multiple interphases within one particle. ${ }^{12,15}$ However, at lower charge rates, since the nanosized $\mathrm{LiFePO}_{4}$ particles react very quickly (a few particles at a time), the patterns from the two end-member phases dominate the $\mathrm{XRD}$ response, and the response is essentially indistinguishable from that seen for scheme $\mathbf{B}$ in Figure $1 .{ }^{16}$ The nonequilibrium single-phase mechanism (D) should be contrasted to that expected for a thermodynamically stable solid solution, where the peaks shift continuously from those of the fully lithiated to the fully delithiated phase (scheme $\mathbf{C}$ in Figure 1). If in scheme A (the bulk two-phase reaction) there is some coherency at the interface, there will be a distortion at the interface of the two phases to reduce the strain, leading to the final scheme, the coherent interface model (E). The subtle differences between schemes $\mathbf{E}$ and $\mathbf{A}$ and how they are manifested in the in situ powder XRD patterns of the nanoparticulate olivine materials will be discussed in detail in this paper.

Here, to explore the delithiation mechanisms occurring within the olivine class of cathode materials, we study the $\mathrm{LiFe}_{x} \mathrm{Co}_{1-x} \mathrm{PO}_{4}$ series $(x=0,0.05,0.125,0.25,0.5,0.75,0.875$, $0.95,1)$. Complex in situ XRD patterns are generally observed for nanoparticulate cation-substituted olivine materials upon cycling, with both solid-solution and two-phase behavior at low cycle rates, ${ }^{14,17}$ suggesting that the mechanism of (de)lithiation deviates from those of the nonsubstituted materials. For example, in the $\mathrm{Mn}$-substituted series $\mathrm{LiFe}_{x} \mathrm{Mn}_{1-x} \mathrm{PO}_{4}$, an intermediate phase, $\mathrm{Li}_{y} \mathrm{Fe}_{x} \mathrm{Mn}_{1-x} \mathrm{PO}_{4}$, was observed in the in situ XRD patterns and exhibited a larger $\mathrm{Li}$ solubility than the end members, $\mathrm{LiFe}_{x} \mathrm{Mn}_{1-x} \mathrm{PO}_{4}$ and $\mathrm{Fe}_{x} \mathrm{Mn}_{1-x} \mathrm{PO}_{4}{ }^{14}$ A two-phase mechanism between $\mathrm{LiFe}_{x} \mathrm{Mn}_{1-x} \mathrm{PO}_{4}$ and $\mathrm{Li}_{y} \mathrm{Fe}_{x} \mathrm{Mn}_{1-x} \mathrm{PO}_{4}$ was observed upon charge, but a bulk single-phase transformation (mechanism C) between the two phases was then seen upon discharge. Substitution on the transition metal site in the olivine cathode materials is thought to facilitate the single-phase mechanism, ${ }^{17-19}$ helping to improve the rate performance of 
the cathode materials, as demonstrated in vanadium-substituted $\mathrm{LiFePO}_{4}{ }^{20}$

Very different mechanisms are observed for the Co-containing olivines: Ehrenberg and co-workers observed by in situ XRD that the delithiation mechanism of the end member $\mathrm{LiCoPO}_{4}$ occurs via a $\mathrm{Li}_{y} \mathrm{CoPO}_{4}$ intermediate with two distinct reactions occurring: $\mathrm{LiCoPO}_{4} \rightarrow \mathrm{Li}_{y} \mathrm{CoPO}_{4}$ and $\mathrm{Li}_{y} \mathrm{CoPO}_{4} \rightarrow \mathrm{CoPO}_{4}{ }^{21,22}$ The processes result in significant loss of long-range order. ${ }^{23}$ In our previous study using in situ XRD and ex situ NMR spectroscopy, ${ }^{24}$ we showed that the intermediate phase has the composition $\mathrm{Li}_{2 / 3}\left(\mathrm{Co}^{3+}\right)_{1 / 3}\left(\mathrm{Co}^{2+}\right)_{2 / 3} \mathrm{PO}_{4}$, its structure being obtained by an $(a \times 3 b \times c)$ supercell expansion of the primitive olivine unit cell. Here we systematically monitor the changes in the in situ XRD patterns for high and low substitution levels of both Fe and Co and then analyze how these changes can be understood within the different delithiation reaction schemes (using Figure 1 as a guide). This allows us to develop a systematic understanding of how substitution affects the complex reaction mechanisms in this series.

We first present XRD characterization of the as-synthesized materials in the $\mathrm{LiFe}_{x} \mathrm{Co}_{1-x} \mathrm{PO}_{4}$ series (section 3.1). We then consider Fe-rich $\mathrm{LiFe}_{x} \mathrm{Co}_{1-x} \mathrm{PO}_{4}(x \geq 0.875)$ and use wholepowder-pattern fitting as described by Liu et al. ${ }^{12}$ to study the first 1.5 cycles (section 3.2). We next study the highly substituted materials, $\mathrm{LiFe}_{0.5} \mathrm{Co}_{0.5} \mathrm{PO}_{4}$ and $\mathrm{LiFe}_{0.25} \mathrm{Co}_{0.75} \mathrm{PO}_{4}$, and identify the intermediates that are formed upon charging the cosubstituted olivines (section 3.3). Relevant NMR spectra are presented to confirm the bulk oxidation changes. Using XRD patterns, refinements, and simulations, we discuss in detail the nature of any coherent interfaces formed during a two-phase reaction and explain how they are manifested in the XRD patterns. We compare the delithiation mechanisms for the transformations between the starting, intermediate, and final phases as a function of Co content. We show that the relationships between the different mechanisms are determined by the length of the coherent interface, the ability of the material to tolerate intermediate $\mathrm{Li}$ compositions, the extent of disorder of $\mathrm{Li}^{+} /$vacancies and $\mathrm{Fe}^{3+} / \mathrm{Co}^{2+}$, and the change in volume between the two end-member phases. From the study of the whole series, trends emerge that were not apparent when single compositions were investigated individually.

\section{EXPERIMENTAL DETAILS}

2.1. Solid-State Synthesis of $\mathrm{LiFe}_{x} \mathrm{Co}_{1-x} \mathrm{PO}_{4}$. The carbon-coated series $\mathrm{LiFe}_{x} \mathrm{Co}_{1-x} \mathrm{PO}_{4}(x=1,0.95,0.875,0.75,0.5,0.25,0.125,0.05,0)$ were synthesized via the solid-state method using iron oxalate (SigmaAldrich, 99.997\%), cobalt oxalate (Sigma-Aldrich), lithium carbonate (Sigma-Aldrich, 99.997\%), ammonium dihydrogen phosphate (SigmaAldrich, 99.999\%), and 10 wt \% Ketjen black (AzkoNobel) in stoichiometric mixtures. After high-energy ball milling for $20 \mathrm{~min}$, each reaction mixture was pelletized and heated to $600{ }^{\circ} \mathrm{C}$ under flowing argon. For $x=1,0.95$, and 0.875 , the precursors were heated for $6 \mathrm{~h} .{ }^{25}$ For $x=0.75$, they were heated for $6 \mathrm{~h}$, cooled, and reheated for a further $11 \mathrm{~h}$. For $\mathrm{LiFe}_{x} \mathrm{Co}_{1-x} \mathrm{PO}_{4}(x=0.5,0.25,0.125,0.05,0)$, the precursors were heated for $6 \mathrm{~h}$ and then cooled and reheated twice for $11 \mathrm{~h}$ before a final $24 \mathrm{~h}$ heating step. The additional heating and cooling steps were carried out to decrease the amount of impurities present in the final product.

2.2. Film Fabrication and Battery Assembly for the in Situ XRD Studies. The electrode was prepared by grinding 85 wt \% carboncoated $\mathrm{LiFe}_{x} \mathrm{Co}_{1-x} \mathrm{PO}_{4}, 5$ wt \% Super P carbon (Alfa Aesar), 5 wt \% carbon black (Vulcan XC-72, Cabot Corporation), and 5 wt \% polytetrafluoroethylene (PTFE) (Sigma-Aldrich) in a mortar and pestle. The powder was pressed into a $13 \mathrm{~mm}$ diameter pellet with a thickness of $\sim 150 \mu \mathrm{m}$ and a mass of $\sim 22 \mathrm{mg}$. The AMPIX ${ }^{26}$ cell was assembled in an argon-filled glovebox using Li metal as the counter electrode, a Whatman GF/B borosilicate microfiber filter as the separator, and a $1 \mathrm{M}$ solution of $\mathrm{LiPF}_{6}$ in a 1:1 mixture of ethylene carbonate/dimethyl carbonate as the electrolyte (Tomiyama Pure Chemical Industries).

2.3. In Situ XRD. In situ XRD experiments were performed at the powder diffraction beamline, 11-BM, at the Advanced Photon Source (APS) at Argonne National Laboratory (ANL) using a 12-channel analyzer detector array $(\lambda=0.413609 \AA$, beam size $1.5 \mathrm{~mm} \times 0.5 \mathrm{~mm}){ }^{27}$ Data spanning a $2 \theta$ range of $0-26^{\circ}$ were collected using a step size of $0.002^{\circ}$. To increase the experiment throughput, multiple batteries were assembled on a motorized stage and translated into the X-ray beam periodically for diffraction measurements. For $x=0.95,0.875,0.125$, and 0.05 , each measurement took $10 \mathrm{~min} 42 \mathrm{~s}$ (using a time per step of $0.34 \mathrm{~s}$ ), and scans were obtained every $60 \min 25 \mathrm{~s}$. For $x=1,0.75,0.5$, 0.25 , and 0 , more scans were acquired during parts of the electrochemical cycling where large structural changes had been observed to occur in earlier preliminary measurements on these samples. All of these scans took $7 \mathrm{~min} 40 \mathrm{~s}$ (the time per step was $0.23 \mathrm{~s}$ ). Since the sampling of the electrochemical processes was nonuniform for these batteries, the points where scans were taken are shown in Figures S1 and S2 in the Supporting Information (SI) and in the main text (for the first charge) as indicated in the figure captions. All of the batteries for the in situ XRD experiments were galvanostatically cycled at a rate of $\mathrm{C} / 20$ using a Maccor model 4300 cycler. The current was continuously applied while the samples were automatically moved in and out of the beam on the sample stage, so that they did not have a chance to "relax". A rate of C/20 was used for three reasons: (a) The scan time for one XRD pattern took $10 \min 42 \mathrm{~s}$ (for $x=1,0.75,0.5,0.25$, and 0 ), which at a rate of $\mathrm{C} / 20$ corresponds to change in state of charge of $<0.9 \%$, which we thought was small enough to result in minimal peak broadening or other artifacts. (b) Since we were studying six cells simultaneously, with scans taking 10 min $42 \mathrm{~s}$, if we cycled at $\mathrm{C} / 20$, we could collect on average $\sim 20$ data points on the charge. As these materials are known for having more than one plateau, we felt that it was important to collect as many data points as realistically possible. (c) We wanted all of the materials to reach highly charged states (i.e., to remove as much $\mathrm{Li}$ as possible), and since the Co-containing materials show poorer electrochemistry than $\mathrm{LiFePO}_{4}$ at higher rates, we chose a moderately low cycle rate. Rietveld refinements were performed using the Topas Academic software. ${ }^{28}$ The individual XRD patterns, Rietveld refinements, and difference plots for patterns from the in situ XRD data for $\mathrm{LiFePO}_{4}$ during the first charge at $8 \%$, 57\%, and 99\% state of charge are shown in Figure S3.

2.4. Whole-Powder-Pattern Fitting of the in Situ XRD Patterns. The same method as discussed in our earlier paper ${ }^{12}$ was used in this study. The background was described by the Chebyshev polynomial. The instrumental broadening was assumed to be negligible and was not considered in the refinement; hence, the broadening of the diffraction peak was attributed solely to the size and strain effects of the sample.

A Lorentzian peak profile was used to model the size broadening, and the apparent size was assumed to be isotropic with respect to different $h k l$ reflections. The dependence of the full width at half-maximum (fwhm), $\beta$, on $\theta$ is given by

$$
\beta=\frac{\lambda}{L \cos \theta_{h k l}}
$$

where $\lambda$ is the wavelength and $L$ is the refined apparent size parameter. The strain/compositional effect was described by a convolution of symmetrical and asymmetrical profile functions. A Gaussian profile peak function was chosen to model the symmetrical broadening due to strain, and this strain was also assumed to be isotropic with respect to different $h k l$ reflections. The $\theta$ dependence of the fwhm is given by

$$
\beta=E \tan \theta_{h k l}
$$

where $E$ is the refined symmetrical strain parameter. The asymmetrical profile was modeled using an exponential function:

$$
f(\theta)=\exp \left(-\frac{2 \theta-2 \theta_{h k l}}{\varepsilon_{\mathrm{m}}}\right)
$$

where $\varepsilon_{\mathrm{m}}$ is the refined parameter and $\theta$ is defined in the range $\left[\theta_{h k l}+\infty\right]$ for $\varepsilon_{\mathrm{m}}>0$ and $\left[-\infty, \theta_{h k l}\right]$ for $\varepsilon_{\mathrm{m}}<0$. Because of the anisotropic changes 
in the lattice parameters going from $\mathrm{LiFe}_{x} \mathrm{Co}_{1-x} \mathrm{PO}_{4}$ to $\mathrm{Fe}_{x} \mathrm{Co}_{1-x} \mathrm{PO}_{4}$, where $a$ and $b$ contract and $c$ expands, we had to include an $h k l$-dependent description of the asymmetrical profile, which was done by including a symmetrized spherical harmonics series in $\varepsilon_{\mathrm{m}}$ :

$$
\varepsilon_{\mathrm{m}}=\sum_{i j} C_{i j} Y_{i j}(\omega, \varphi) \tan \theta_{h k l}
$$

where $Y_{i j}(\omega, \varphi)$ are the symmetrized spherical harmonics ${ }^{29,30}$ and $C_{i j}$ are the refined parameters.

The pure strain-induced profile for a certain $h k l$ reflection was obtained by convoluting the symmetrical Gaussian function and the exponential function defined at the corresponding $\theta_{h k l}$. This convoluted profile corresponds to the variation of the lattice parameters. The population density function (pdf) on the $2 \theta$ scale for an $h k l$ interplanar spacing of one phase is given by

$$
\operatorname{pdf}(2 \theta)_{h k l}=\frac{1}{E \sqrt{2 \pi}} \mathrm{e}^{-\left(2 \theta-2 \theta_{h k l}\right)^{2} / 2 E^{2}} \otimes f(\theta)
$$

where $E$ is the refined symmetrical strain parameter defined in eq 2 and $f(\theta)$ is given by eq 3 . The population densities of the $a, b$, and $c$ lattice parameters for one phase are given by $\mathrm{pdf}_{200}, \mathrm{pdf}_{020}$, and $\mathrm{pdf}_{002}$ respectively. The total population density (considering both Li-rich and Li-poor phases) is given by

$$
\operatorname{pdf}(2 \theta)=\mathrm{SF}_{1} \times \operatorname{pdf}(2 \theta)_{h k l, 1}+\mathrm{SF}_{2} \times \operatorname{pdf}(2 \theta)_{h k l, 2}
$$

where $\mathrm{SF}_{1}$ and $\mathrm{SF}_{2}$ are the scale factors for the Li-rich and Li-poor phases, respectively. Bragg's law was used to convert the scale from $2 \theta$ to $d$-spacing.

The whole-powder-pattern fitting of the in situ diffraction patterns within the $2 \theta$ range between $3.5^{\circ}$ and $15^{\circ}$ was carried out sequentially using the TOPAS structural refinement package. ${ }^{31}$

2.5. Simulations of XRD Peak Profiles for a Coherent Interface. A cubic particle with edges parallel to the $a, b$, and $c$ axes of the olivine crystal structure was used for the simulation. Each edge was $100 \mathrm{~nm}$ long. The interface was assumed to be perpendicular to the [h00] direction, and the $\mathrm{Li}$ concentration and lattice parameter profiles along the $[h 00]$ direction were assumed to take the following form:

$$
a(x)=\frac{a_{0}+a_{1}}{2}+\frac{a_{1}-a_{0}}{2} \tanh \left(\frac{2}{L}\left(x-x_{0}\right)\right)
$$

where $a_{0}$ and $a_{1}$ represent the values of the quantity ( $\mathrm{Li}$ concentration or lattice parameter) for the two end-member phases, respectively, $L$ is the width of the interface, $x_{0}$ is the central position of the interface, and $x$ is the coordinate along the $[h 00]$ direction. The delithiation process was simulated in discrete steps by varying $x_{0}$ from one end of the particle to the other. The value of $x_{0}$ was determined in such a way as to make sure the global Li concentration was consistent with the state of charge.

The X-ray diffraction intensity was simulated following the treatment by Warren. ${ }^{32}$ For a $0 k 0$ reflection, the diffraction power as a function of diffraction angle $2 \theta$ can be expressed as

$$
P(2 \theta)=\frac{K}{\sin ^{2} \theta} \sum_{m^{\prime}} \sum_{m} f_{m^{\prime}} f_{m} \mathrm{e}^{(2 \pi \mathrm{i} / \lambda)(2 \sin \theta)\left(R_{m^{\prime}}-R_{m}\right)}
$$

where the subscripts $m$ and $m^{\prime}$ represent the indices of the unit cells, $f_{m}$ is the structure factor of unit cell $m, R_{m}$ is the position coordinate of unit cell $m, \lambda$ is the X-ray wavelength, and $K$ is a factor independent of $\theta$. The summation is performed over all of the unit cells in the particle. The structure factor $f$ for the 020 reflection was assumed to vary linearly with the Li composition $c:^{33}$

$$
f(c)=(1-c) f(0)+c f(1)
$$

where $f(0)$ is the structure factor for the 020 reflection of $\mathrm{Fe}_{0.25} \mathrm{Co}_{0.75} \mathrm{PO}_{4}$ and $f(1)$ is that for $\mathrm{LiFe}_{0.25} \mathrm{Co}_{0.75} \mathrm{PO}_{4}$.

\section{RESULTS AND DISCUSSION}

3.1. Synthesis and Characterization of $\mathrm{LiFe}_{x} \mathrm{Co}_{1-x} \mathrm{PO}_{4}$. The carbon-coated $\mathrm{LiFe}_{x} \mathrm{Co}_{1-x} \mathrm{PO}_{4}(x=0,0.05,0.125,0.25,0.5$,
$0.75,0.875,0.95,1)$ materials were synthesized via solid-state synthesis. Additional heating steps were required for higher Co compositions to decrease the extent of impurities present in the product (including $\mathrm{Li}_{3} \mathrm{PO}_{4}$, as shown in Figure S4). ${ }^{25}$ The average particle size of $\mathrm{LiFePO}_{4}$ is approximately $120 \mathrm{~nm}$, as determined from scanning electron microscopy (SEM) images of a $\mathrm{LiFePO}_{4}$ electrode taken at different magnifications (shown in the SI). The large distribution of particle sizes (from 50 to $350 \mathrm{~nm}$ ) and spherical-type morphology are expected for the solid-state synthesis. ${ }^{34,35}$ SEM images of the as-synthesized carbon-coated $\mathrm{LiCoPO}_{4}$ powder indicate that the particle size is smaller than $50 \mathrm{~nm}$ (see Figure S5). Therefore, the particle sizes of all of the $\mathrm{LiFe}_{x} \mathrm{Co}_{1-x} \mathrm{PO}_{4}$ compositions are assumed to be in the nanoparticulate regime.

3.2. Fe-Rich $\mathrm{LiFe}_{x} \mathrm{Co}_{1-x} \mathrm{PO}_{4}(x=1,0.95,0.875)$. 3.2.1. First Charge. In situ XRD patterns of the Fe-rich substituted olivines $\left(\mathrm{LiFePO}_{4}, \mathrm{LiFe}_{0.95} \mathrm{Co}_{0.05} \mathrm{PO}_{4}\right.$, and $\left.\mathrm{LiFe}_{0.875} \mathrm{Co}_{0.125} \mathrm{PO}_{4}\right)$ cycled at a rate of $\mathrm{C} / 20$ for the first cycle and up to $100 \mathrm{~mA} \mathrm{~h}^{-1} \mathrm{~g}^{-1}$ of the second charge are presented in Figure $2 \mathrm{a}-\mathrm{c}$, respectively. The $2 \theta$ range in Figure $2 \mathrm{a}-\mathrm{c}$ shows the 020 and 211 reflections of the lithiated and delithiated phases. Only the $\mathrm{FePO}_{4}$ and $\mathrm{LiFePO}_{4}$ reflections are observed when $\mathrm{LiFePO}_{4}$ is charged at this low rate (Figure 2a). This is characteristic of a "two-phase reaction" at the electrode level, the delithiated phase being formed at the expense of the fully lithiated phase with no significant peak shift and broadening (as discussed in the Introduction). We cannot determine the exact mechanism of the reaction at the single-particle level, i.e., we cannot distinguish whether two phases exist within the same particles or in different particles, at intermediate states of charge, as depicted in schemes A and $\mathbf{B}$ in Figure 1, ${ }^{6,10}$ because of the limited resolution of the experimental setup and the limited fraction of the sample that is expected to be undergoing a transformation (delithiation) at one time at the low rates used here.

In both $\mathrm{LiFe}_{0.95} \mathrm{Co}_{0.05} \mathrm{PO}_{4}$ and $\mathrm{LiFe}_{0.875} \mathrm{Co}_{0.125} \mathrm{PO}_{4}$, the evolution of the intensities and positions of the reflections of the end-member lithiated phase on charging is similar to that observed for $\mathrm{LiFePO}_{4}$. In contrast, the peak positions of the delithiated phases deviate noticeably from the positions of $\mathrm{Fe}_{x} \mathrm{Co}_{1-x} \mathrm{PO}_{4}$, shifting toward that of the $\mathrm{Li}_{0}$ phase as charging proceeds. The extent of the deviations becomes more significant as the Co content increases.

Rietveld refinements were carried out using the XRD data, and the changes in the unit cell volumes as a function of capacity are plotted in Figure $2 \mathrm{~d}-\mathrm{f}$. The theoretical capacity of $\mathrm{LiFe}_{x} \mathrm{Co}_{1-x} \mathrm{PO}_{4}$ is between 167 and $170 \mathrm{~mA} \mathrm{~h}^{-1} \mathrm{~g}^{-1}$. However, as shown in Figure 2e,f, the charge capacities for the Co-containing materials are noticeably larger than expected as a result of side reactions (potentially including oxidation of the electrolyte above $4.6 \mathrm{~V}$, the formation of a solid electrolyte interphase (SEI) at the cathode, ${ }^{36,37}$ metal dissolution, ${ }^{38}$ and oxidation of carbon). Nevertheless, the discharge capacities are among the highest recorded for these materials $\left(\sim 160 \mathrm{~mA} \mathrm{~h}^{-1} \mathrm{~g}^{-1}\right.$; Table S1 and Figure S6), suggesting that the reversibility of the electrochemical reactions is not significantly affected by the side reactions, at least in the first few cycles.

Since the $\mathrm{Fe}^{2+} \rightarrow \mathrm{Fe}^{3+}$ and $\mathrm{Co}^{2+} \rightarrow \mathrm{Co}^{3+}$ redox reactions occur at $\sim 3.5$ and $\sim 4.8 \mathrm{~V}$, respectively, in the olivine structure, $\mathrm{Fe}^{2+}$ is oxidized first upon charging. Therefore, the particles must have a $\mathrm{Li}$ content of $\mathrm{Li}_{1-x} \mathrm{Fe}_{x} \mathrm{Co}_{1-x} \mathrm{PO}_{4}$ at the end of the $3.6 \mathrm{~V}$ process because $x \mathrm{Li}$ per formula unit is deintercalated during the Fe plateau. A continual and gradual shift of the unit cell volume is observed going from the $\mathrm{Li}_{1-x}\left(\mathrm{Fe}^{3+}\right)_{x}\left(\mathrm{Co}^{2+}\right)_{1-x} \mathrm{PO}_{4}$ phase to the fully delithiated $\left(\mathrm{Fe}^{3+}\right)_{x}\left(\mathrm{Co}^{3+}\right)_{1-x} \mathrm{PO}_{4}$ material upon charging at $>3.5 \mathrm{~V}$ 
In situ X-ray Diffraction Patterns
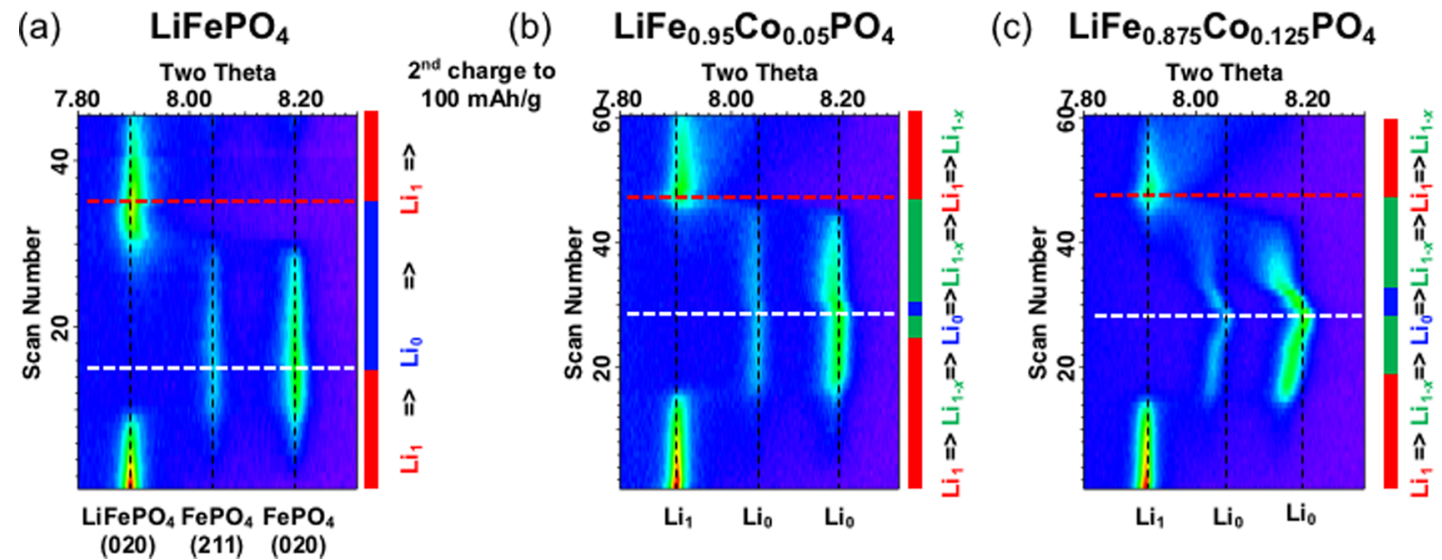

Figure 2. In situ XRD data for the first cycle and up to $100 \mathrm{~mA} \mathrm{~h}^{-1} \mathrm{~g}^{-1}$ of the second charge of the Fe-rich $\mathrm{LiFe}_{x} \mathrm{Co}_{1-x} \mathrm{PO}_{4}$ phases $(x=1,0.95$, and 0.875 in $(\mathrm{a}-\mathrm{c})$, respectively) while cycling at a rate corresponding to $\mathrm{C} / 20$. Here and in all of the XRD patterns presented in this paper, the $x$ axis displays the $2 \theta$ region $=7.8-8.3^{\circ}(\lambda=0.413609 \AA)$, showing the characteristic 020 and 211 reflections of the end-member phases. The $y$ axis represents the scan number. These scan numbers correspond to the red crosses (and blue boxes) marked on the electrochemical data in ( $d-f$ ). The black dotted vertical lines indicate the positions of the peaks of the fully lithiated and delithiated phases. Unit cell volume changes as a function of capacity (in $\left.\mathrm{mA} \mathrm{h}^{-1} \mathrm{~g}^{-1}\right)$ for $x=1,0.95$, and 0.875 are shown in (d) $-(\mathrm{f})$, respectively. The black line represents the electrochemistry, while the red crosses, blue squares represent the volumes of the $\mathrm{LiFe}_{x} \mathrm{Co}_{1-x} \mathrm{PO}_{4} \mathrm{Fe}_{x} \mathrm{Co}_{1-x} \mathrm{PO}_{4}$ phases, respectively. Variations of the $b$ lattice parameter, plotted as the population density, as a function of the scan number for $x=1,0.95$, and 0.875 are shown in $(\mathrm{g}-\mathrm{i})$ respectively (extracted from refinements using whole-powder-pattern fits). The $b$ lattice parameters for the lithiated and delithiated phases are $\sim 6.0$ and $5.8 \AA$, respectively. The $(\mathrm{a}-\mathrm{c})$ white and $(\mathrm{g}-\mathrm{i})$ black dashed horizontal lines indicate the end of the charge, while the red dashed lines represent the end of the discharge. The red, green, and blue bars alongside the figure show when the $\mathrm{Li}_{1}{ }^{-}$, $\mathrm{Li}_{1-x^{-}}$, and $\mathrm{Li}_{0} \mathrm{Fe}_{x} \mathrm{Co}_{1-x} \mathrm{PO}_{4}$ phases, respectively, are being consumed.

(Figures 2e,f), which is indicative of a single-phase transition between the two $\mathrm{Li}$ stoichiometries at the bulk (electrode) level (mechanism C) for the $\mathrm{Co}^{2+} / \mathrm{Co}^{3+}$ process. Ex situ ${ }^{31} \mathrm{P} \mathrm{NMR}$ spectra of the fully charged material confirm the complete transformation of these phases to $\mathrm{Fe}_{x} \mathrm{Co}_{1-x} \mathrm{PO}_{4}$ (Figure S7).

3.2.2. Subsequent Cycles: The Discrete Nonequilibrium Single-Phase Mechanism (D). As shown in Figure $2 \mathrm{a}-\mathrm{c}$ the first discharge and second charge appear to have different in situ XRD responses compared with the first charge. The sharp reflections from the pristine structure are not reformed after the first cycle, instead, the reflections are broader and asymmetric (the individual diffraction patterns are plotted in Figure S8). Additionally, low-intensity, continually shifting peaks are observed between the $\mathrm{LiFe}_{x} \mathrm{Co}_{1-x} \mathrm{PO}_{4}, \mathrm{Li}_{1-x} \mathrm{Fe}_{x} \mathrm{Co}_{1-x} \mathrm{PO}_{4}$, and $\mathrm{Fe}_{x} \mathrm{Co}_{1-x} \mathrm{PO}_{4}$ reflections in the first discharge and second charge, which correspond to compositions with intermediate stoichiometries. The patterns qualitatively resemble those observed by Liu et al. ${ }^{12}$ during very fast cycling of $\mathrm{LiFePO}_{4}$, this phenomenon being attributed to the nonequilibrium single-phase, particle-by-particle delithiation mechanism of $\mathrm{LiFePO}_{4}$ (mechanism D).

Following the work of Liu et al., ${ }^{12}$ we used whole-powderpattern fitting to obtain population densities describing the fractions of the sample exhibiting different cell parameters. The population densities of the $b$ lattice parameters for $\mathrm{LiFePO}_{4}$, $\mathrm{LiFe}_{0.95} \mathrm{Co}_{0.05} \mathrm{PO}_{4}$, and $\mathrm{LiFe}_{0.875} \mathrm{Co}_{0.125} \mathrm{PO}_{4}$ plotted as a function of scan number for the first 1.5 cycles are shown in Figure $2 \mathrm{~g}-\mathrm{i}$, respectively. Liu et al. ${ }^{12}$ observed that $\mathrm{Li}_{1-\delta} \mathrm{FePO}_{4}$ can accommodate a larger deviation in the $a, b$, and $c$ lattice parameters from the end member $\mathrm{LiFePO}_{4}$ than $\mathrm{Li}_{8} \mathrm{FePO}_{4}$ can from $\mathrm{FePO}_{4}$ (after the first charge). This is supported by phase-field simulations ${ }^{39}$ and in situ XRD experiments, ${ }^{25,40}$ both of which show that $\mathrm{Li}_{1-\delta} \mathrm{FePO}_{4}$ is able to exist in a larger single-phase region than $\mathrm{Li}_{\delta} \mathrm{FePO}_{4}$. When $5 \% \mathrm{Co}$ is substituted onto the Fe site, the $\mathrm{Li}_{0.05} \mathrm{Fe}_{0.95} \mathrm{Co}_{0.05} \mathrm{PO}_{4}$ intermediate can tolerate an even larger range of cell parameters beyond those observed for $\mathrm{LiFe}_{0.95} \mathrm{Co}_{0.05} \mathrm{PO}_{4}$ and
$\mathrm{Fe}_{0.95} \mathrm{Co}_{0.05} \mathrm{PO}_{4}$. This becomes apparent upon discharge. The effect is more pronounced for $\mathrm{LiFe}_{0.875} \mathrm{Co}_{0.125} \mathrm{PO}_{4}$, which upon discharge first shows bulk single-phase (solid solution) behavior (mechanism C) between fully delithiated $\mathrm{Fe}_{0.875} \mathrm{Co}_{0.125} \mathrm{PO}_{4}$ and the intermediate $\mathrm{Li}_{0.125} \mathrm{Fe}_{0.875} \mathrm{Co}_{0.125} \mathrm{PO}_{4}$ (i.e., a continuous shift of the diffraction peaks, with a narrow distribution in the $b$ lattice parameter); this is then followed by an asymmetric broadening in the diffraction peaks, reflecting a large dispersion of lattice parameters $/ d$-spacings. This asymmetric broadening is a deviation from the conventional two-phase reaction and is suggestive of a single-phase, nonequilibrium transformation between $\mathrm{Li}_{0.125} \mathrm{Fe}_{0.875} \mathrm{Co}_{0.125} \mathrm{PO}_{4}$ and $\mathrm{LiFe}_{0.875} \mathrm{Co}_{0.125} \mathrm{PO}_{4}$ (mechanism D).

The results in Figure 2 strongly suggest that the nonequilibrium single-phase behavior (D), previously observed only at high rates, is present even under the application of a low current. The presence of Co substituted into the $\mathrm{LiFePO}_{4}$ structure results in more particles reacting at the same time, making it easier to detect the single-phase behavior. However, there is still evidence of the nonequilibrium single-phase transition at low cycle rates even for $\mathrm{LiFePO}_{4}$. Interestingly, more particles react simultaneously in the first discharge and second charge compared with the first charge. This same phenomenon was also observed at high rates for $\mathrm{LiFePO}_{4}$, i.e., the asymmetric peak broadening (and hence the nonequilibrium limits of the solid solution) is more significant in the first discharge and subsequent cycles than in the first charge. ${ }^{12}$ The origin of this phenomenon is not clear, but it may be related to the presence of nonequilibrium $\mathrm{Li}^{+}$ion concentrations within the electrolyte, particularly when the experiments are performed at high rates; simulations are required to explore this hypothesis. The introduction of disorder in the lattice via the formation of defects (particularly in the case of the Co-substituted materials) or due to the presence of residual $\mathrm{Li}$ ions or vacancies in the delithated and lithiated materials, respectively, may also result in an increase in the entropy of the system and a reduction in the tendency of the system to order, promoting solid-solution behavior. 
(a)

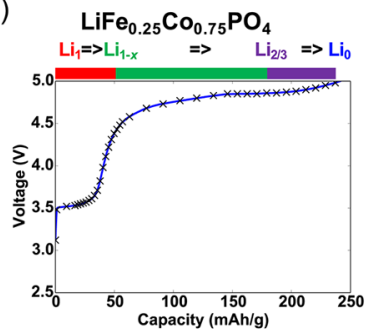

(c)

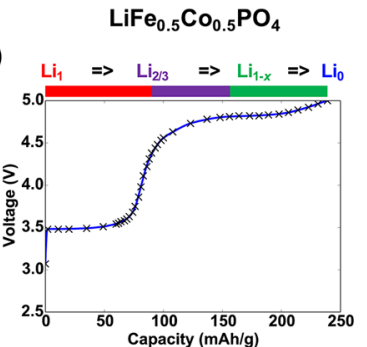

(b)

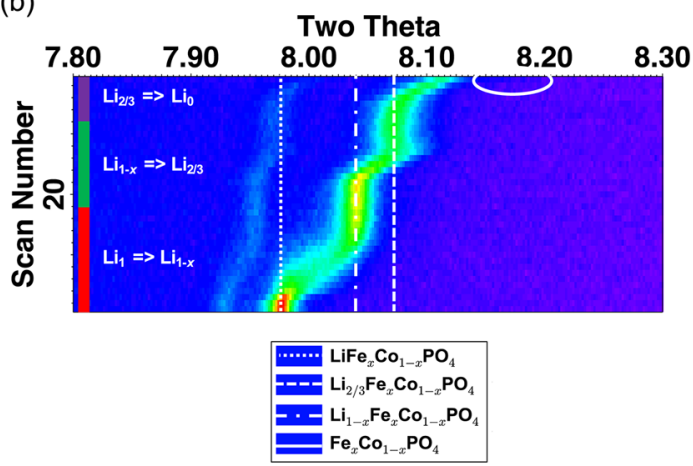

(d)

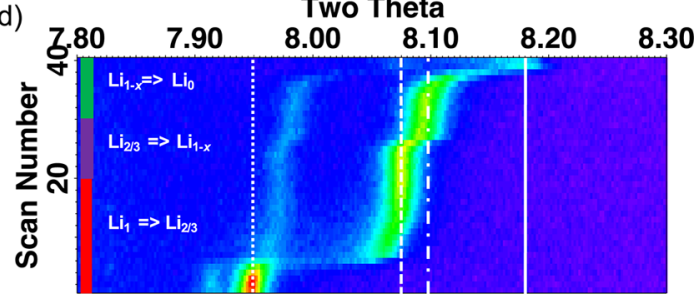

Figure 3. First-charge XRD data for (a, b) $\mathrm{LiFe}_{0.25} \mathrm{Co}_{0.75} \mathrm{PO}_{4}$ and $(c, d) \mathrm{LiFe}_{0.5} \mathrm{Co}_{0.5} \mathrm{PO}_{4}$ charged at a cycle rate of $\mathrm{C} / 20$. The electrochemistry collected during the in situ XRD experiments is shown by the blue solid lines in (a) and (c), and the black crosses indicate the times at which the XRD patterns were collected, i.e., when the scans commenced. The in situ XRD patterns vs scan number are shown in (b) and (d). The white lines represent the lattice parameters of the $\mathrm{LiFe}_{x} \mathrm{Co}_{1-x} \mathrm{PO}_{4}, \mathrm{Fe}_{x} \mathrm{Co}_{1-x} \mathrm{PO}_{4}, \mathrm{Li}_{2 / 3} \mathrm{Fe}_{x} \mathrm{Co}_{1-x} \mathrm{PO}_{4}$, and $\mathrm{Li}_{1-x} \mathrm{Fe}_{x} \mathrm{Co}_{1-x} \mathrm{PO}_{4}$ phases. The white ellipse indicates the calculated position of the 020 reflection for the delithiated phase, $\mathrm{Fe}_{0.25} \mathrm{Co}_{0.75} \mathrm{PO}_{4}$, obtained using Vegard's law and the cell parameters of $\mathrm{FePO}_{4}$ and $\mathrm{CoPO}_{4}$. The red, green, and purple bars alongside the figure show when the $\mathrm{Li}_{1}-, \mathrm{Li}_{1-x^{-}}$, and $\mathrm{Li}_{2 / 3} \mathrm{Fe}_{x} \mathrm{Co}_{1-x} \mathrm{PO}_{4}$ phases, respectively, are being consumed in the reaction.

3.3. Highly Co-Substituted Phases. 3.3.1. $\mathrm{LiFe}_{0.25} \mathrm{Co}_{0.75} \mathrm{PO}_{4}$ and $\mathrm{LiFe}_{0.5} \mathrm{CO}_{0.5} \mathrm{PO}_{4}$. The electrochemistry and in situ XRD patterns for the first charge of the highly substituted olivine material, $\mathrm{LiFe}_{0.25} \mathrm{Co}_{0.75} \mathrm{PO}_{4}$, are shown in Figure 3a,b. In agreement with the Fe-rich materials, the intermediate, $\mathrm{Li}_{1-x} \mathrm{Fe}_{x} \mathrm{Co}_{1-x} \mathrm{PO}_{4}$, is seen at the end of the $\mathrm{Fe}^{2+} / \mathrm{Fe}^{3+}$ redox plateau. Interestingly, a second intermediate is also observed, which on the basis of our previous study of $\mathrm{LiCoPO}_{4}$, in which a $\mathrm{Li}_{2 / 3} \mathrm{CoPO}_{4}$ intermediate was identified, has the Li stoichiometry $\mathrm{Li}_{2 / 3} \mathrm{Fe}_{x} \mathrm{Co}_{1-x} \mathrm{PO}_{4} \cdot{ }^{24} \mathrm{Using}$ Vegard's law and assuming a constant variation in the lattice parameters across the series $\mathrm{Fe}_{x} \mathrm{Co}_{1-x} \mathrm{PO}_{4}(0 \leq x \leq 1)$ and $\mathrm{Li}_{y} \mathrm{Fe}_{0.25} \mathrm{Co}_{0.75} \mathrm{PO}_{4}(0 \leq y \leq 1)$, we can estimate the expected lattice parameters for $\mathrm{Fe}_{0.25} \mathrm{Co}_{0.75} \mathrm{PO}_{4}$ (the resulting approximate position of the 020 reflection is shown with a white ellipse in Figure 3). Surprisingly, the reflections from $\mathrm{Fe}_{0.25} \mathrm{Co}_{0.75} \mathrm{PO}_{4}$ are difficult to detect in Figure $3 \mathrm{~b}$ during the first charge, despite a capacity of over $91 \%$ of the theoretical capacity (i.e., $153 \mathrm{~mA} \mathrm{~h}^{-1} \mathrm{~g}^{-1}$, compared with the theoretical capacity of $167.75 \mathrm{~mA} \mathrm{~h}^{-1} \mathrm{~g}^{-1}$ ) in both the first and second cycles. The fully delithiated phase is, however, more clearly seen in the second cycle (see Figure S9), and close inspection of the individual XRD patterns at the end of first charge, as shown in Figure S9, does reveal small, weak reflections at the same positions observed for $\mathrm{Fe}_{0.25} \mathrm{Co}_{0.75} \mathrm{PO}_{4}$ in the second cycle.

The in situ XRD patterns for the first charge of $\mathrm{LiFe}_{0.5} \mathrm{Co}_{0.5} \mathrm{PO}_{4}$ (Figure 3d) also contain reflections from two intermediate compositions in addition to those of the fully lithiated and delithiated materials. On the basis of Vegard analysis, they are assigned to $\mathrm{Li}$ stoichiometries of $\mathrm{Li}_{2 / 3}$ and $\mathrm{Li}_{1-x}$. This is in very good agreement with the first charge of the $\mathrm{LiFe}_{0.25} \mathrm{Co}_{0.75} \mathrm{PO}_{4}$ material. Interestingly, both intermediates are formed during the $\mathrm{Fe}^{2+} / \mathrm{Fe}^{3+}$ plateau, with $\mathrm{Li}_{2 / 3} \mathrm{Fe}_{0.5} \mathrm{Co}_{0.5} \mathrm{PO}_{4}$ forming first, followed by $\mathrm{Li}_{0.5} \mathrm{Fe}_{0.5} \mathrm{Co}_{0.5} \mathrm{PO}_{4}$. The $\mathrm{Li}_{0.5} \mathrm{Fe}_{0.5} \mathrm{Co}_{0.5} \mathrm{PO}_{4}$ phase forms at a charge capacity of $137 \mathrm{~mA} \mathrm{~h}^{-1} \mathrm{~g}^{-1}$ (which is $81.3 \%$ of the theoretical capacity of $168.5 \mathrm{~mA} \mathrm{~h}^{-1} \mathrm{~g}^{-1}$ ). However, as already discussed, the capacities of the first charge are significantly higher than the theoretical capacities as a result of side reactions, SEI formation, and/or electrolyte decomposition. Therefore, in order to determine the $\mathrm{Li}$ composition of this intermediate, we use (a) the unit cell volume, which by Vegard's law indicates that the phase has a stoichiometry of $\mathrm{Li}_{0.48}$, and (b) the voltage at which the $\mathrm{Li}_{0.5} \mathrm{Fe}_{0.5} \mathrm{Co}_{0.5} \mathrm{PO}_{4}$ phase forms, $\sim 4.78 \mathrm{~V}$ (i.e., after the $\mathrm{Fe}^{2+} / \mathrm{Fe}^{3+}$ redox plateau and before the higher-voltage $\mathrm{Co}^{2+} /$ $\mathrm{Co}^{3+}$ plateau).

3.3.2. The Coherent Interface. A whole-powder-pattern fit was performed for $\mathrm{LiFe}_{0.25} \mathrm{Co}_{0.75} \mathrm{PO}_{4}$, and the population density plot of the $b$ lattice parameter is shown as a function of scan number in Figure 4a. The first intermediate, $\mathrm{Li}_{0.75} \mathrm{Fe}_{0.25} \mathrm{Co}_{0.75} \mathrm{PO}_{4}$, is formed via a two-phase reaction from the fully lithiated phase. It can be seen that $\mathrm{LiFe}_{0.25} \mathrm{Co}_{0.75} \mathrm{PO}_{4}$ and $\mathrm{Li}_{0.75} \mathrm{Fe}_{0.25} \mathrm{Co}_{0.75} \mathrm{PO}_{4}$ have significant $\mathrm{Li}$ solubility ranges. To study this first phase transition more closely, the individual XRD patterns (in the $2 \theta$ range containing the 020 and 211 reflections) for the beginning of charge $\left(\mathrm{LiFe}_{0.25} \mathrm{Co}_{0.75} \mathrm{PO}_{4} \rightarrow \mathrm{Li}_{0.75} \mathrm{Fe}_{0.25} \mathrm{Co}_{0.75} \mathrm{PO}_{4}\right)$ are shown in Figure $4 \mathrm{~b}$. When the $\mathrm{Li}_{0.75} \mathrm{Fe}_{0.25} \mathrm{Co}_{0.75} \mathrm{PO}_{4}$ phase first nucleates in the parent phase (fully lithiated $\mathrm{LiFe}_{0.25} \mathrm{Co}_{0.75} \mathrm{PO}_{4}$ particles), the volume extends toward the volume of $\mathrm{LiFe}_{0.25} \mathrm{Co}_{0.75} \mathrm{PO}_{4}$, which results in a shift in the XRD peak position (Figure $4 \mathrm{~b}$ ), suggesting the presence of a coherent interface between the two phases within the same particle (mechanism $\mathbf{E}$ in Figure 1 and Figure $4 \mathrm{~b}) .{ }^{14}$ The same is observed when $\mathrm{LiFe}_{0.25} \mathrm{Co}_{0.75} \mathrm{PO}_{4}$ is the minority phase in the $\mathrm{Li}_{0.75} \mathrm{Fe}_{0.25} \mathrm{Co}_{0.75} \mathrm{PO}_{4}$ particle.

The distortion in the crystal structure of the minority phase as it nucleates in the majority phase arises from the structural elasticity in the minority phase, which allows it to be accommodated in the majority phase of the particle while reducing the energy at the interface of the two phases. Hence, there is both a change in intensity in the Bragg diffraction peaks (as the nucleating phase grows at the expense of the parent phase) and a shift in the peak 


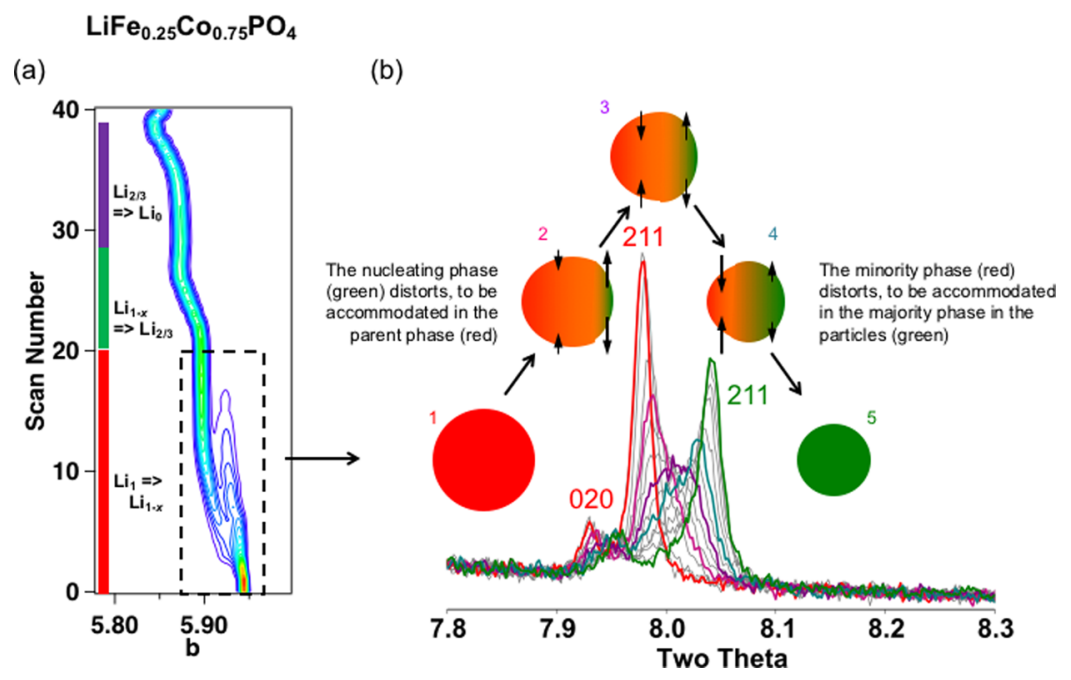

Figure 4. (a) Variations of the $b$ lattice parameter of $\mathrm{LiFe}_{0.25} \mathrm{Co}_{0.75} \mathrm{PO}_{4}$, plotted as the population density, as a function of the scan number, extracted from refinements using whole-powder-pattern fits. (b) XRD patterns of the phase transition from $\mathrm{LiFe}_{0.25} \mathrm{Co}_{0.75} \mathrm{PO}_{4}$ to $\mathrm{Li}_{0.75} \mathrm{Fe}_{0.25} \mathrm{Co}_{0.75} \mathrm{PO}_{4}$ (i.e., scan numbers 0-20, the region highlighted by the black dashed line in (a)). The XRD response is characteristic of a coherently nucleating phase (i.e., $\mathrm{Li}_{0.75} \mathrm{Fe}_{0.25} \mathrm{Co}_{0.75} \mathrm{PO}_{4}$, represented in green) in the parent-phase particle (where red represents $\mathrm{LiFe}_{0.25} \mathrm{Co}_{0.75} \mathrm{PO}_{4}$ ). The five cartoons labeled 1-5 represent the states of transforming particles at times corresponding to the red, pink, purple, teal, and green diffraction patterns (at capacities of $0,37,80$, 103 , and $115 \mathrm{~mA} \mathrm{~h}^{-1} \mathrm{~g}^{-1}$, respectively, representing scan numbers $1,5,8,10$, and 15 , respectively). The red, green, and purple bars alongside the figure indicate when the $\mathrm{Li}_{1^{-}}, \mathrm{Li}_{1-x^{-}}$, and $\mathrm{Li}_{2 / 3} \mathrm{Fe}_{x} \mathrm{Co}_{1-x} \mathrm{PO}_{4}$ phases, respectively, are being consumed in the reaction.

positions due to the structural distortions. This phenomenon is observed to a degree in all of the two-phase reactions but is much more pronounced in phase transformations of the highly substituted samples; it was nonetheless clearly visible in the $\mathrm{LiCoPO}_{4}$ to $\mathrm{Li}_{2 / 3} \mathrm{CoPO}_{4}$ reaction. ${ }^{24}$

XRD peak profile simulations were carried out on $100 \mathrm{~nm}$ cubic $\mathrm{LiFe}_{0.25} \mathrm{Co}_{0.75} \mathrm{PO}_{4}$ particles. Two-phase reactions between $\mathrm{LiFe}_{0.25} \mathrm{Co}_{0.75} \mathrm{PO}_{4}$ and $\mathrm{Li}_{0.75} \mathrm{Fe}_{0.25} \mathrm{Co}_{0.75} \mathrm{PO}_{4}$, between $\mathrm{Li}_{0.75} \mathrm{Fe}_{0.25} \mathrm{Co}_{0.75} \mathrm{PO}_{4}$ and $\mathrm{Li}_{2 / 3} \mathrm{Fe}_{0.25} \mathrm{Co}_{0.75} \mathrm{PO}_{4}$, and between $\mathrm{Li}_{2 / 3} \mathrm{Fe}_{0.25} \mathrm{Co}_{0.75} \mathrm{PO}_{4}$ and $\mathrm{Fe}_{0.25} \mathrm{Co}_{0.75} \mathrm{PO}_{4}$ were modeled with a coherent interface ranging between 5 and $200 \mathrm{~nm}$ in length as described in section 2.5. The length of the interface is the quantity $L$ that appears in eq 7 , which describes a concentration profile along the $a$ axis of the particle. When the length of the interface approaches or becomes greater than the size of the particle $(100 \mathrm{~nm})$, the concentration gradient spans across the entire particle, which does not have two well-defined phases and appears more like a single-phase solid solution. (Representative concentration profiles are illustrated in Figure S10.) It should be noted that when the coherent interface is $200 \mathrm{~nm}$ in size, the peaks continually and gradually shift from the reactants to the products, i.e., the response approaches that expected for a bulk single-phase mechanism (scheme $\mathrm{C}$ ). The results for the evolution of the $020 \mathrm{XRD}$ peak are shown in Figure 5. There is reasonable agreement between the simulation and the experimental data of the coherent interface: the peaks of the minority phase distort significantly toward the values of the majority phase (Figure 5c). The simulations suggest that the $\mathrm{LiFe}_{0.25} \mathrm{Co}_{0.75} \mathrm{PO}_{4} \rightarrow$ $\mathrm{Li}_{1-x} \mathrm{Fe}_{x} \mathrm{Co}_{1-x} \mathrm{PO}_{4}$ reaction proceeds via the two-phase mechanism with a coherent interface for which $60<L<100 \mathrm{~nm}$. In contrast, the $\mathrm{Li}_{1-x} \mathrm{Fe}_{x} \mathrm{Co}_{1-x} \mathrm{PO}_{4} \rightarrow \mathrm{Li}_{2 / 3} \mathrm{Fe}_{x} \mathrm{Co}_{1-x} \mathrm{PO}_{4}$ and $\mathrm{Li}_{2 / 3} \mathrm{Fe}_{x} \mathrm{Co}_{1-x} \mathrm{PO}_{4} \rightarrow \mathrm{Fe}_{x} \mathrm{Co}_{1-x} \mathrm{PO}_{4}$ reactions both show continuous and gradual shifts in the XRD peaks, corresponding to the two-phase mechanism with a coherent interface for which $L=200 \mathrm{~nm}$, i.e., the bulk solid-solution mechanism.

It should be noted that we have assumed the nucleating phase growing within the majority component has the same composition and thus cell parameters as the bulk phase, with the composition varying across the interface. It is also important to emphasize that more than one coherent interface may exist in one particle simultaneously.

3.3.3. Systematic Analysis of Cell Parameter Changes. The same analysis as described in section 3.3.1 for $\mathrm{LiFe}_{0.25} \mathrm{Co}_{0.75} \mathrm{PO}_{4}$ and $\mathrm{LiFe}_{0.5} \mathrm{Co}_{0.5} \mathrm{PO}_{4}$ was carried out for all of the other $\mathrm{LiFe}_{x} \mathrm{Co}_{1-x} \mathrm{PO}_{4}$ phases $(x=1,0.95,0.875,0.75,0.125,0.05,0)$. The cell parameters for the intermediates and end-member phases for all nine ratios were extracted from Rietveld refinements of the XRD patterns (all of the raw data is shown in Figure S11). The unit cell volumes of the end members and intermediates extracted from the Rietveld refinements of the XRD patterns are plotted against $\mathrm{Fe}$ content $(x)$ in Figure 6 . The phases corresponding to $\mathrm{LiFe}_{x} \mathrm{Co}_{1-x} \mathrm{PO}_{4}, \mathrm{Li}_{1-x} \mathrm{Fe}_{x} \mathrm{Co}_{1-x} \mathrm{PO}_{4}, \mathrm{Li}_{2 / 3} \mathrm{Fe}_{x} \mathrm{Co}_{1-x} \mathrm{PO}_{4}$, and $\mathrm{Fe}_{x} \mathrm{Co}_{1-x} \mathrm{PO}_{4}$ are shown by red, green, purple, and blue data points, respectively. There is a linear increase in the volume of $\mathrm{LiFe}_{x} \mathrm{Co}_{1-x} \mathrm{PO}_{4}$ (shown in red) with increasing $x$. This is in agreement with the literature ${ }^{41,42}$ and is a result of the homogeneous mixing of the transition metals in the olivine structure (assuming that Vegard's law applies). Similarly, the $a$ and $b$ lattice parameters (shown in Figure S12) increase with increasing $\mathrm{Fe}$ content because of the larger ionic radius of $\mathrm{Fe}^{2+}$ compared with $\mathrm{Co}^{2+}$ (92 and $88.5 \mathrm{pm}$, respectively, assuming a high-spin ion in an octahedral environment). ${ }^{43}$ Interestingly, the $c$ axis decreases with increasing $\mathrm{Fe}$ content, and although the origin for this behavior is unknown, it is thought to be related to the stiffness of the $\mathrm{P}-\mathrm{O}$ bonds (effectively rigid $\mathrm{PO}_{4}$ tetrahedra) and the shared edges between the $\mathrm{PO}_{4}$ and $\mathrm{MO}_{6}$ polyhedra, ${ }^{41}$ with the phosphate ions acting to separate or pillar the chains of edge-sharing $\mathrm{MO}_{6}$ octahedra. The changes in the volume for $\mathrm{Fe}_{x} \mathrm{Co}_{1-x} \mathrm{PO}_{4}$ (blue dashed line) display the same linear gradient as those for the lithiated phases, presumably because the difference in Co and $\mathrm{Fe}$ cation sizes is identical for the divalent and trivalent cations. The volume of the $\mathrm{Li}_{2 / 3} \mathrm{Fe}_{x} \mathrm{Co}_{1-x} \mathrm{PO}_{4}$ intermediate (observed for the Co-majority materials, $0 \leq x \leq 0.5$ ) lies two-thirds of the way between those of the fully lithiated and delithiated phases 

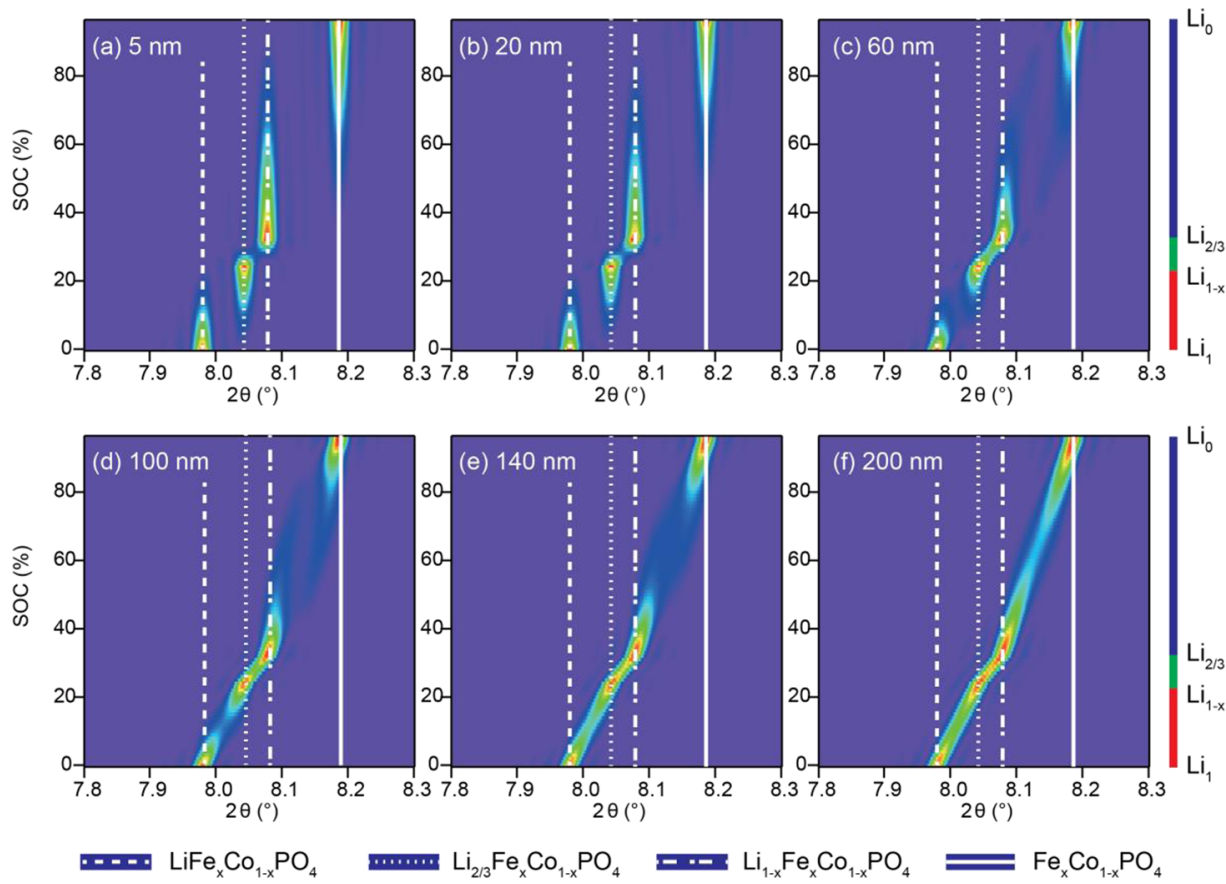

Figure 5. Simulations of the evolution of $020 \mathrm{XRD}$ peak profiles for a two-phase reaction with a coherent interface between $\mathrm{LiFe}_{0.25} \mathrm{Co}_{0.75} \mathrm{PO}_{4}$ and $\mathrm{Li}_{0.75} \mathrm{Fe}_{0.25} \mathrm{Co}_{0.75} \mathrm{PO}_{4}$, between $\mathrm{Li}_{0.75} \mathrm{Fe}_{0.25} \mathrm{Co}_{0.75} \mathrm{PO}_{4}$ and $\mathrm{Li}_{2 / 3} \mathrm{Fe}_{0.25} \mathrm{Co}_{0.75} \mathrm{PO}_{4}$, and between $\mathrm{Li}_{2 / 3} \mathrm{Fe}_{0.25} \mathrm{Co}_{0.75} \mathrm{PO}_{4}$ and $\mathrm{Fe}_{0.25} \mathrm{Co}_{0.75} \mathrm{PO}_{4}$ in $100 \mathrm{~nm} \mathrm{sized}$ cubic $\mathrm{LiFe}_{0.25} \mathrm{Co}_{0.75} \mathrm{PO}_{4}$ particles, assuming that the interface is (a) $5 \mathrm{~nm}$, (b) $20 \mathrm{~nm}$, (c) $60 \mathrm{~nm},(\mathrm{~d}) 100 \mathrm{~nm},(\mathrm{e}) 140 \mathrm{~nm}$, and (f) $200 \mathrm{~nm}$ in size at

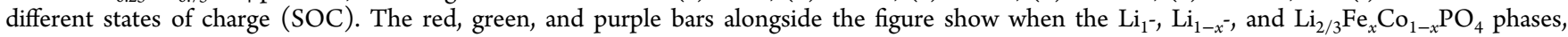
respectively, are being consumed in the reaction.

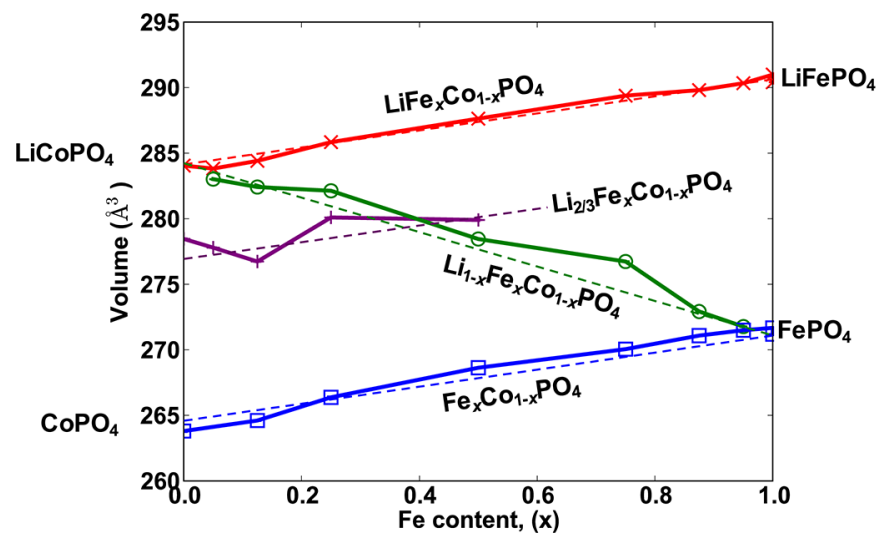

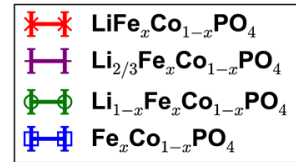

Linear relationship from:

-..- $\mathrm{LiFePO}_{4}$ to $\mathrm{LiCOPO}_{4}$

-.-- $\mathrm{FePO}_{4}$ to $\mathrm{CoPO}_{4}$

- - $\mathrm{Li}_{2 / 3} \mathrm{CoPO}_{4}$ to $\mathrm{Li}_{2 / 3} \mathrm{Fe}_{0.5} \mathrm{Co}_{0.5} \mathrm{PO}_{4}$

-.- $\mathrm{LiCOPO}_{4}$ to $\mathrm{FePO}_{4}$

Figure 6. Unit cell volumes of the end-member and intermediate phases observed when $\mathrm{LiFe}_{x} \mathrm{Co}_{1-x} \mathrm{PO}_{4}$ is delithiated. The red dashed line represents linear volume changes in going from $\mathrm{LiFePO}_{4}$ to $\mathrm{LiCoPO}_{4}$ calculated using the end-member volumes. The same gradient as used for the lithiated phases (red) was used for the delithiated and $\mathrm{Li}_{2 / 3} \mathrm{Fe}_{x} \mathrm{Co}_{1-x} \mathrm{PO}_{4}$ materials (blue and purple dashed lines, respectively). The blue line was drawn to go through the delithiated unit cell volume data, and the purple line was placed two-thirds of the way between the delithiated and lithiated data (i.e., it is not a fit to the data). The green dashed line simply connects the experimental cell volumes of $\mathrm{LiCoPO}_{4}$ and $\mathrm{FePO}_{4}$.

(purple dashed line), and the volume of the $\mathrm{Li}_{1-x} \mathrm{Fe}_{x} \mathrm{Co}_{1-x} \mathrm{PO}_{4}$ intermediates varies linearly between those of $\mathrm{LiCoPO}_{4}$ and $\mathrm{FePO}_{4}$ with increasing Fe content (green dashed line). This simple analysis using Vegard's rule is in good agreement with the Li stoichiometries assigned to the intermediates observed during the first charge of $\mathrm{LiFe}_{x} \mathrm{Co}_{1-x} \mathrm{PO}_{4}(x=0.95,0.875,0.75,0.5,0.125,0.05)$. Although no obvious trends for the compositions and cell parameters of the different intermediates emerge when each composition is studied individually, the systematic examination of the phases as a function of Fe:Co ratio reveals clear correlations with respect to the Li composition and cell parameters of the intermediate phases.

The percentage differences in the $a, b$, and $c$ axes, the $a b, a c$, and $b c$ planes, and the volumes of the two intermediates and the end-member structures relative to $\mathrm{LiFePO}_{4}$ have been calculated and are shown in Figure $\mathrm{S} 13$. As was observed in the $\mathrm{LiFe}_{x} \mathrm{Mn}_{1-x} \mathrm{PO}_{4}$ materials ${ }^{14}$ and for $\mathrm{LiCoPO}_{4}{ }^{24}$ there is a very small difference $(<2 \%)$ in the $b c$ plane among all of the structures. This strongly suggests that when there is a coherent interface, it is likely to be in this plane, resulting in the lowest size mismatch and therefore the lowest strain compared with interfaces along the $a b$ and $b c$ planes. This arises from the contraction of the $c$ axis with both increasing Co content and decreasing $\mathrm{Li}$ content from $\mathrm{LiFePO}_{4}$ and the smaller expansion along the $b$ axis compared with the $a$ axis. We now consider separately how the delithiation mechanisms vary among the starting, intermediate, and end-member phases, comparing the mechanisms as a function of Co content. 
3.4. $\mathrm{LiFe}_{x} \mathrm{Co}_{1-x} \mathrm{PO}_{4}$ Delithiation Mechanisms upon Charging. 3.4.1. Delithiation Mechanisms between the Two Intermediates $\mathrm{Li}_{1-x} \mathrm{Fe}_{x} \mathrm{Co}_{1-x} \mathrm{PO}_{4}$ and $\mathrm{Li}_{2 / 3} \mathrm{Fe}_{x} \mathrm{CO}_{1-x} \mathrm{PO}_{4}$. As shown in Figure 6, when the four substituted olivines $\mathrm{LiFe}_{0.05} \mathrm{Co}_{0.95} \mathrm{PO}_{4}, \quad \mathrm{LiFe}_{0.125} \mathrm{Co}_{0.875} \mathrm{PO}_{4}, \quad \mathrm{LiFe}_{0.25} \mathrm{Co}_{0.75} \mathrm{PO}_{4}$, and $\mathrm{LiFe}_{0.5} \mathrm{Co}_{0.5} \mathrm{PO}_{4}$ are delithiated, two intermediates are observed, $\mathrm{Li}_{1-x} \mathrm{Fe}_{x} \mathrm{Co}_{1-x} \mathrm{PO}_{4}$ and $\mathrm{Li}_{2 / 3} \mathrm{Fe}_{x} \mathrm{Co}_{1-x} \mathrm{PO}_{4}$. We now investigate in more detail how the structural transformation between these two intermediate phases occurs. We start with this transformation because it is the simplest mechanism observed in this system. A whole-powder-pattern fit was performed for all four materials during the delithiation between the two intermediates, and the population density plots of the $b$ lattice parameter as a function of scan number are shown in Figure 7 (for clarity, only the $b$ lattice parameter changes are shown here; the $a, b$, and $c$ lattice parameter changes can be found in Figures S14-S16). The decrease in the intensity of the lattice parameter population densities for $\mathrm{LiFe}_{0.05} \mathrm{Co}_{0.95} \mathrm{PO}_{4}$ is attributed to the loss of long-range order, similar to that observed upon charging of $\mathrm{LiCoPO}_{4}$. For the three higher-Fe-content materials, continuous intensity connecting the lattice parameters of the $\mathrm{Li}_{1-x} \mathrm{Fe}_{x} \mathrm{Co}_{1-x} \mathrm{PO}_{4}$ and $\mathrm{Li}_{2 / 3} \mathrm{Fe}_{x} \mathrm{Co}_{1-x} \mathrm{PO}_{4}$ phases is observed, providing evidence for a bulk single-phase transformation (mechanism C). This is noticeably different from the response in the lattice parameters observed for both the discrete nonequilibrium single-phase mechanism (D) and the two-phase mechanism exhibiting a large coherent interface (shown in Figure $4 b$, mechanism $E$ ).

The single-phase mechanism between the intermediates appears to be preferred because of the disorder of the transition metals on the $\mathrm{Fe} / \mathrm{Co}$ sublattice. The homogeneous mixing of $\mathrm{Fe}^{2+}$ and $\mathrm{Co}^{2+}$ on the transition metal sublattice in the starting materials ${ }^{42}$ results in a random distribution of $\mathrm{Fe}^{3+}$ and $\mathrm{Co}^{2+}$ in the $\mathrm{Li}_{1-x}\left(\mathrm{Fe}^{3+}\right)_{x}\left(\mathrm{Co}^{2+}\right)_{1-x} \mathrm{PO}_{4}$ intermediate. Unless there is an energy gain for $\mathrm{Li}^{+} /$vacancy ordering, this also results in a random distribution of $\mathrm{Li}^{+}$ions in the particles, with $\mathrm{Li}^{+}$ preferentially occupying sites close to $\mathrm{Co}^{2+}$ (or more generally $\mathrm{M}^{2+}$ ) because of the reduction in $\mathrm{Li}^{+}-$transition metal cation repulsive Coulombic interactions arising from the lower charge of $\mathrm{Co}^{2+}$ versus $\mathrm{Fe}^{3+}$. The existence of a distribution of $\mathrm{Li}^{+} /$vacancies and $\mathrm{Fe}^{3+} / \mathrm{Co}^{2+}$ in the $\mathrm{Li}_{1-x} \mathrm{Fe}_{x} \mathrm{Co}_{1-x} \mathrm{PO}_{4}$ intermediate helps favor the bulk single-phase mechanism for the $\mathrm{Co}^{2+} / \mathrm{Co}^{3+}$ process for $\mathrm{LiFe}_{0.05} \mathrm{Co}_{0.95} \mathrm{PO}_{4}, \mathrm{LiFe}_{0.125} \mathrm{Co}_{0.875} \mathrm{PO}_{4}$, and $\mathrm{LiFe}_{0.25} \mathrm{Co}_{0.75} \mathrm{PO}_{4}$. As discussed in section 3.3.1, the $\mathrm{Li}_{2 / 3}$ intermediate is also formed on the $\mathrm{Fe}^{2+} / \mathrm{Fe}^{3+}$ oxidation plateau for $\mathrm{LiFe}_{0.5} \mathrm{Co}_{0.5} \mathrm{PO}_{4}$, which means that this single-phase mechanism also occurs between the intermediates during $\mathrm{Fe}^{2+}$ oxidation. Therefore, it is likely that the single-phase mechanism between the intermediates is also preferred because of the small change in volume between $\mathrm{Li}_{2 / 3} \mathrm{Fe}_{0.5} \mathrm{Co}_{0.5} \mathrm{PO}_{4}$ and $\mathrm{Li}_{1-x} \mathrm{Fe}_{0.5} \mathrm{Co}_{0.5} \mathrm{PO}_{4}$ (see the plot at the bottom of Figure 7).

3.4.2. Delithiation Mechanisms To Form the Fully Delithiated Phase, $\mathrm{Fe}_{x} \mathrm{Co}_{1-x} \mathrm{PO}_{4}$. We now examine the mechanisms that occur to form $\mathrm{Fe}_{x} \mathrm{Co}_{1-x} \mathrm{PO}_{4}$ at the end of the first charge. A wholepowder-pattern fit was performed for $\mathrm{LiFe}_{0.875} \mathrm{Co}_{0.125} \mathrm{PO}_{4}$, $\mathrm{LiFe}_{0.75} \mathrm{Co}_{0.25} \mathrm{PO}_{4}, \mathrm{LiFe}_{0.5} \mathrm{Co}_{0.5} \mathrm{PO}_{4}$, and $\mathrm{LiFe}_{0.125} \mathrm{Co}_{0.875} \mathrm{PO}_{4}$, and the population density plots of the $b$ lattice parameter as a function of scan number in the region of the charge profile when the fully delithiated phase forms are shown in Figure 8. For the Fe-rich samples, this represents the transformation from $\mathrm{Li}_{1-x} \mathrm{Fe}_{x} \mathrm{Co}_{1-x} \mathrm{PO}_{4}$ to $\mathrm{Fe}_{x} \mathrm{Co}_{1-x} \mathrm{PO}_{4}$, while for the higher-Co-content sample $\left(\mathrm{LiFe}_{0.125} \mathrm{Co}_{0.875} \mathrm{PO}_{4}\right)$ this corresponds to a transition from the $\mathrm{Li}_{2 / 3} \mathrm{Fe}_{x} \mathrm{Co}_{1-x} \mathrm{PO}_{4}$ phase. Three samples were not included in this
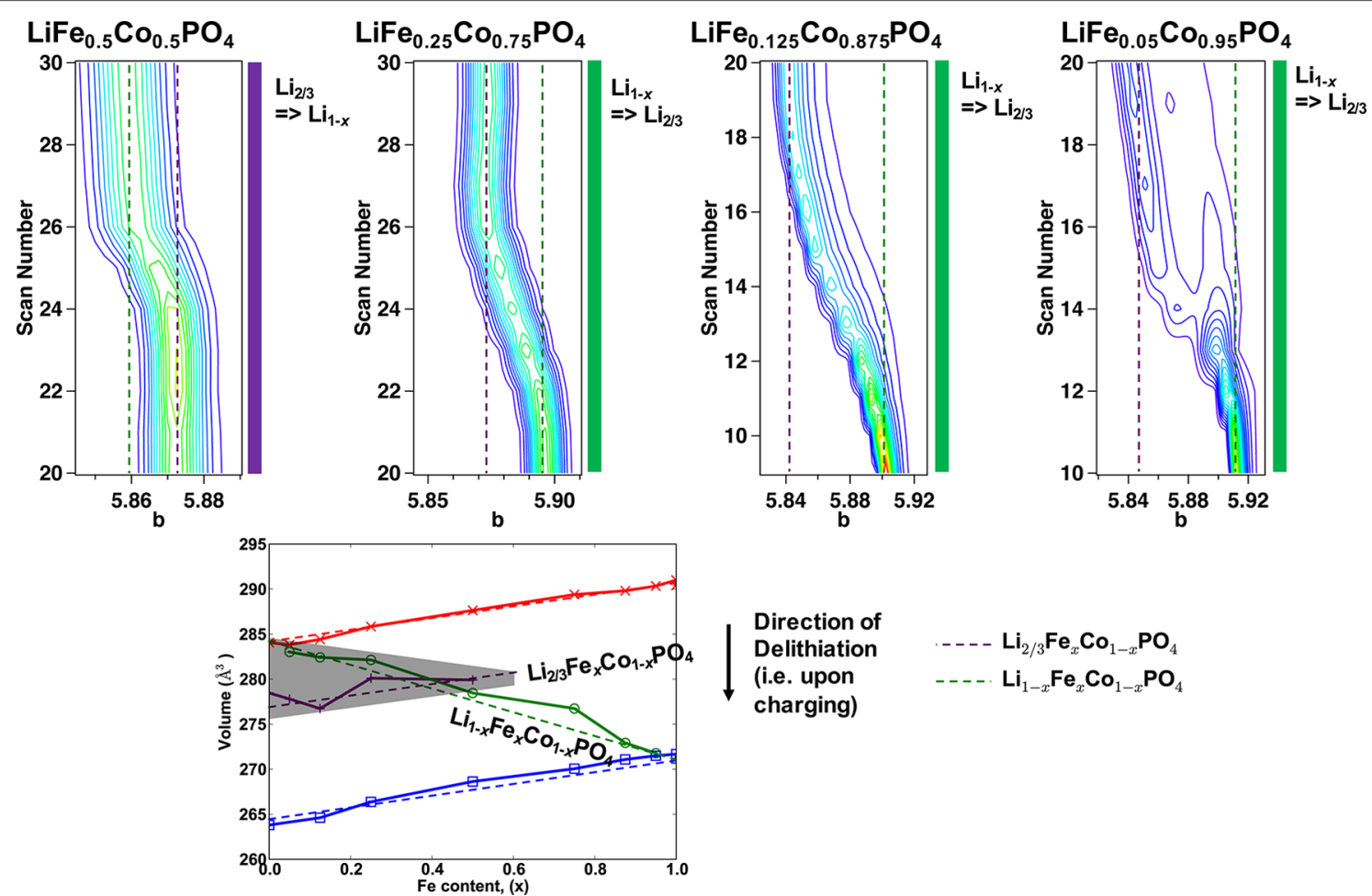

Figure 7. Variations in the $b$ lattice parameter, plotted as population density, as a function of the scan number for $\mathrm{LiFe}_{05} \mathrm{Co}_{0.5} \mathrm{PO}_{4}, \mathrm{LiFe}_{025} \mathrm{Co}_{075} \mathrm{PO}_{4}$ $\mathrm{LiFe}_{0.125} \mathrm{Co}_{0.875} \mathrm{PO}_{4}$, and $\mathrm{LiFe}_{0.05} \mathrm{Co}_{0.95} \mathrm{PO}_{4}$. These were extracted from refinements using whole-powder-pattern fits. The plot at the bottom shows the volume changes between the intermediate phases. The gray-shaded area indicates the phases being investigated in this section and whose cell parameters are shown in this figure. The green and purple bars alongside the plots indicate when the $\mathrm{Li}_{1-x^{-}}$and $\mathrm{Li}_{2 / 3} \mathrm{Fe}_{x} \mathrm{Co}_{1-x} \mathrm{PO}_{4}$ phases, respectively, are being consumed in the reaction. 

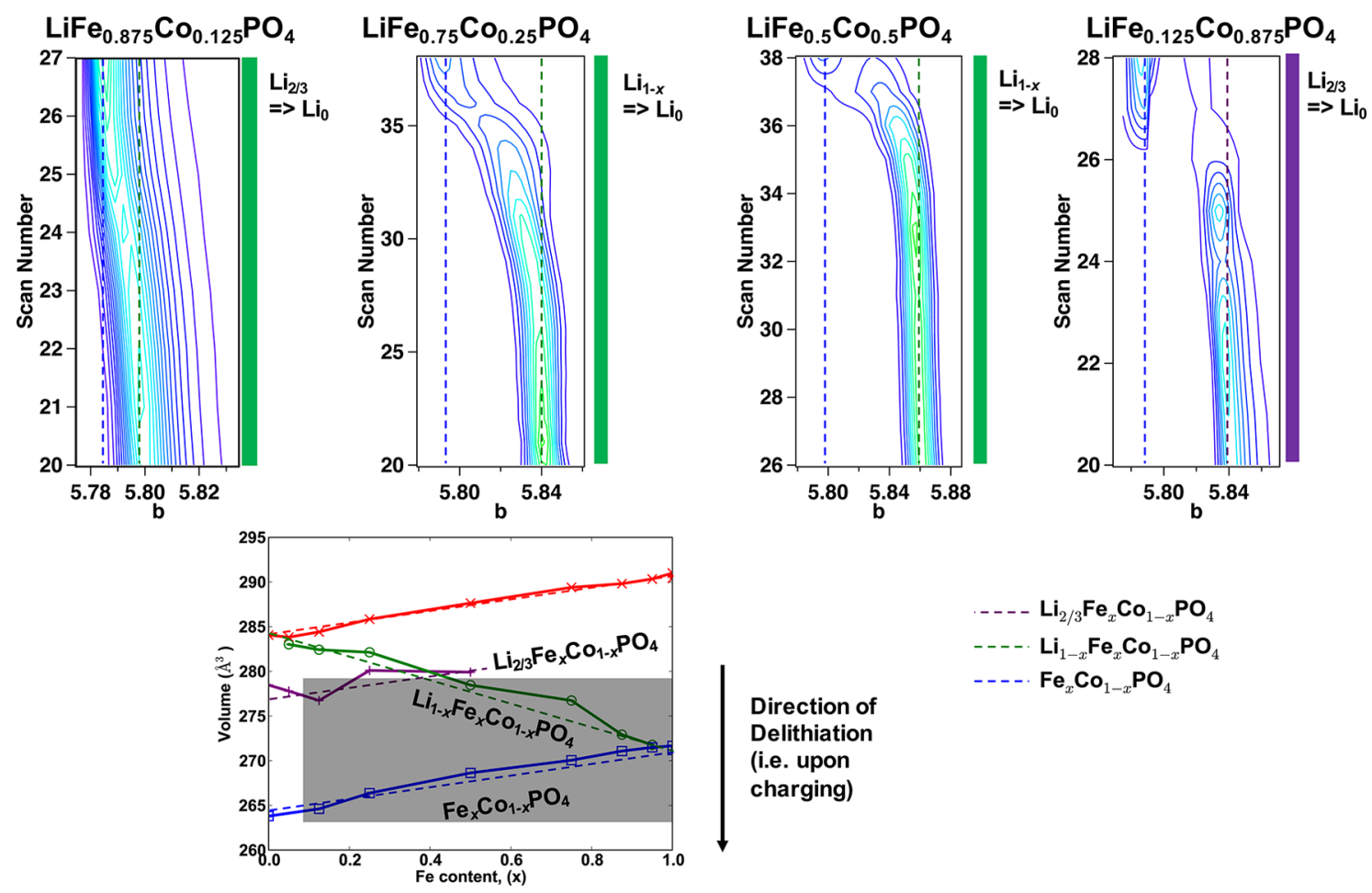

Delithiation

(i.e. upon

harging)

Figure 8. Variations in the $b$ lattice parameter, plotted as population density, as a function of the scan number for $\mathrm{LiFe}_{0.875} \mathrm{Co}_{0.125} \mathrm{PO}_{4}, \mathrm{LiFe}_{0.75} \mathrm{Co}_{0.25} \mathrm{PO}_{4}$, $\mathrm{LiFe}_{0.5} \mathrm{Co}_{0.5} \mathrm{PO}_{4}$, and $\mathrm{LiFe}_{0.125} \mathrm{Co}_{0.875} \mathrm{PO}_{4}$. These were extracted from refinements using whole-powder-pattern fits. The plot at the bottom shows the volume changes as a function of Fe content, and the gray-shaded region indicates the phase changes being investigated in this figure. The green and purple bars alongside the plots show when the $\mathrm{Li}_{1-x^{-}}$and $\mathrm{Li}_{2 / 3} \mathrm{Fe}_{x} \mathrm{Co}_{1-x} \mathrm{PO}_{4}$ phases, respectively, are being consumed in the reaction.

analysis because the fully delithiated phase was not clearly observed on the first charge $\left(\mathrm{LiFe}_{0.25} \mathrm{Co}_{0.75} \mathrm{PO}_{4}\right.$; see section 3.3.1), no XRD patterns were obtained for the full charge (for $\mathrm{LiFe}_{0.05} \mathrm{Co}_{0.95} \mathrm{PO}_{4}$ ) because of time limitations at the synchrotron, and for $\mathrm{LiCoPO}_{4}$ the significant loss of long-range order results in reduced intensity of the Bragg reflections, making the data difficult to interpret using this method of analysis.

When $\mathrm{LiFe}_{0.875} \mathrm{Co}_{0.125} \mathrm{PO}_{4}$ is fully delithiated, there is a continuous and gradual shift in the lattice parameters from the $\mathrm{Li}_{0.125} \mathrm{Fe}_{0.875} \mathrm{Co}_{0.125} \mathrm{PO}_{4}$ phase to $\mathrm{Fe}_{0.875} \mathrm{Co}_{0.125} \mathrm{PO}_{4}$, indicating that the bulk single-phase mechanism (scheme $\mathbf{C}$ ) is observed. As discussed in section 3.4.1, the single-phase mechanism is preferred because of (i) the disorder of $\mathrm{Li}^{+} /$vacancies and $\mathrm{Fe}^{3+} / \mathrm{Co}^{2+}$ in $\mathrm{Li}_{1-x} \mathrm{Fe}_{x} \mathrm{Co}_{1-x} \mathrm{PO}_{4}$, which helps favor the single-phase mechanism during the oxidation of $\mathrm{Co}^{2+}$, and (ii) the small change in volume. For both $\mathrm{LiFe}_{0.75} \mathrm{Co}_{0.25} \mathrm{PO}_{4}$ and $\mathrm{LiFe}_{0.5} \mathrm{Co}_{0.5} \mathrm{PO}_{4}$, single-phase behavior is also observed upon delithiation of $\mathrm{Li}_{1-x} \mathrm{Fe}_{x} \mathrm{Co}_{1-x} \mathrm{PO}_{4}$, but fewer particles appear to react at once compared with $\mathrm{LiFe}_{0.875} \mathrm{Co}_{0.125} \mathrm{PO}_{4}$ (i.e., the number of reacting particles decreases with decreasing $\mathrm{Fe}$ content in going from $\mathrm{LiFe}_{0.875} \mathrm{Co}_{0.125} \mathrm{PO}_{4}$ to $\mathrm{LiFe}_{0.75} \mathrm{Co}_{0.25} \mathrm{PO}_{4}$ to $\left.\mathrm{LiFe}_{0.5} \mathrm{Co}_{0.5} \mathrm{PO}_{4}\right)$. A continuous shift in the lattice parameters can be seen in going from $\mathrm{Li}_{1-x} \mathrm{Fe}_{0.75} \mathrm{Co}_{0.25} \mathrm{PO}_{4}$ to $\mathrm{Fe}_{0.75} \mathrm{Co}_{0.25} \mathrm{PO}_{4}$, whereas for the $\mathrm{Li}_{0.5} \mathrm{Fe}_{0.5} \mathrm{Co}_{0.5} \mathrm{PO}_{4} \rightarrow$ $\mathrm{Fe}_{0.5} \mathrm{Co}_{0.5} \mathrm{PO}_{4}$ reaction significant asymmetric deviations of the end-member phases toward each other are observed. This implies that the single-phase mechanism is to a degree occurring discretely between particles (scheme $\mathbf{D}$ ) rather than simultaneously (i.e., at the bulk level, scheme C). This change from particles reacting discretely compared with simultaneously is even more pronounced during the reaction of $\mathrm{Li}_{2 / 3} \mathrm{Fe}_{0.125} \mathrm{Co}_{0.875} \mathrm{PO}_{4}$ to form $\mathrm{Fe}_{0.125} \mathrm{Co}_{0.875} \mathrm{PO}_{4}$.
To summarize, during the oxidation of $\mathrm{Co}^{2+}$ to $\mathrm{Co}^{3+}$, a singlephase (solid-solution) mechanism occurs within individual particles to form fully delithiated $\mathrm{Fe}_{x} \mathrm{Co}_{1-x} \mathrm{PO}_{4}$. At low levels of Fe substitution (i.e., $\mathrm{LiFe}_{0.125} \mathrm{Co}_{0.875} \mathrm{PO}_{4}$ ), the reaction occurs discretely, particle-by-particle. As the level of Fe substitution increases, more particles react simultaneously, resulting in increasingly more bulk single-phase-like behavior. At high $\mathrm{Fe}$ contents, i.e., $\mathrm{LiFe}_{0.875} \mathrm{Co}_{0.125} \mathrm{PO}_{4}$, essentially ideal single-phase behavior is observed.

3.4.3. Delithiation Mechanisms Occurring during the Reaction of Fully Lithiated $\mathrm{LiFe}_{x} \mathrm{CO}_{1-x} \mathrm{PO}_{4}$. Finally, we examine the first delithiation reaction that occurs upon charging of $\mathrm{LiFe}_{x} \mathrm{Co}_{1-x} \mathrm{PO}_{4}$ for $x=1,0.95,0.8750 .75,0.5,0.25,0.125$, and 0.05 . A wholepowder-pattern fit was performed for all eight of the materials, and the population density plots of the $b$ lattice parameter as a function of scan number are shown in Figure 9 for the initial delithiation of the pristine $\mathrm{LiFe}_{x} \mathrm{Co}_{1-x} \mathrm{PO}_{4}$ phase. $\mathrm{LiCoPO}_{4}$ is not included since we focus here on the mechanism that occurs on the $\mathrm{Fe}^{2+} / \mathrm{Fe}^{3+}$ oxidation plateau.

As discussed in section 3.2, the delithiation of the Fe-rich materials $\left(\mathrm{LiFePO}_{4}, \mathrm{LiFe}_{0.95} \mathrm{Co}_{0.05} \mathrm{PO}_{4}\right.$, and $\left.\mathrm{LiFe}_{0.875} \mathrm{Co}_{0.125} \mathrm{PO}_{4}\right)$ appears to occur via a simple "two-phase" reaction (as only the two end-member phases are observed, as depicted in mechanism B). However, further analysis of the first discharge and second charge reveals that the transformation between the two phases (between $\mathrm{LiFePO}_{4}$ and $\mathrm{FePO}_{4}$ and between $\mathrm{LiFe}_{x} \mathrm{Co}_{1-x} \mathrm{PO}_{4}$ and $\mathrm{Li}_{1-x} \mathrm{Fe}_{x} \mathrm{Co}_{1-x} \mathrm{PO}_{4}$ for $x=0.95$ and 0.875$)$ occurs via the nonequilibrium single-phase mechanism (D). Since very few particles react at once, the two end-member phases dominate the response. As the Co-substitution level increases (from 0 to 0.05 to 0.125 ), more particles react at once and the asymmetric deviations from 

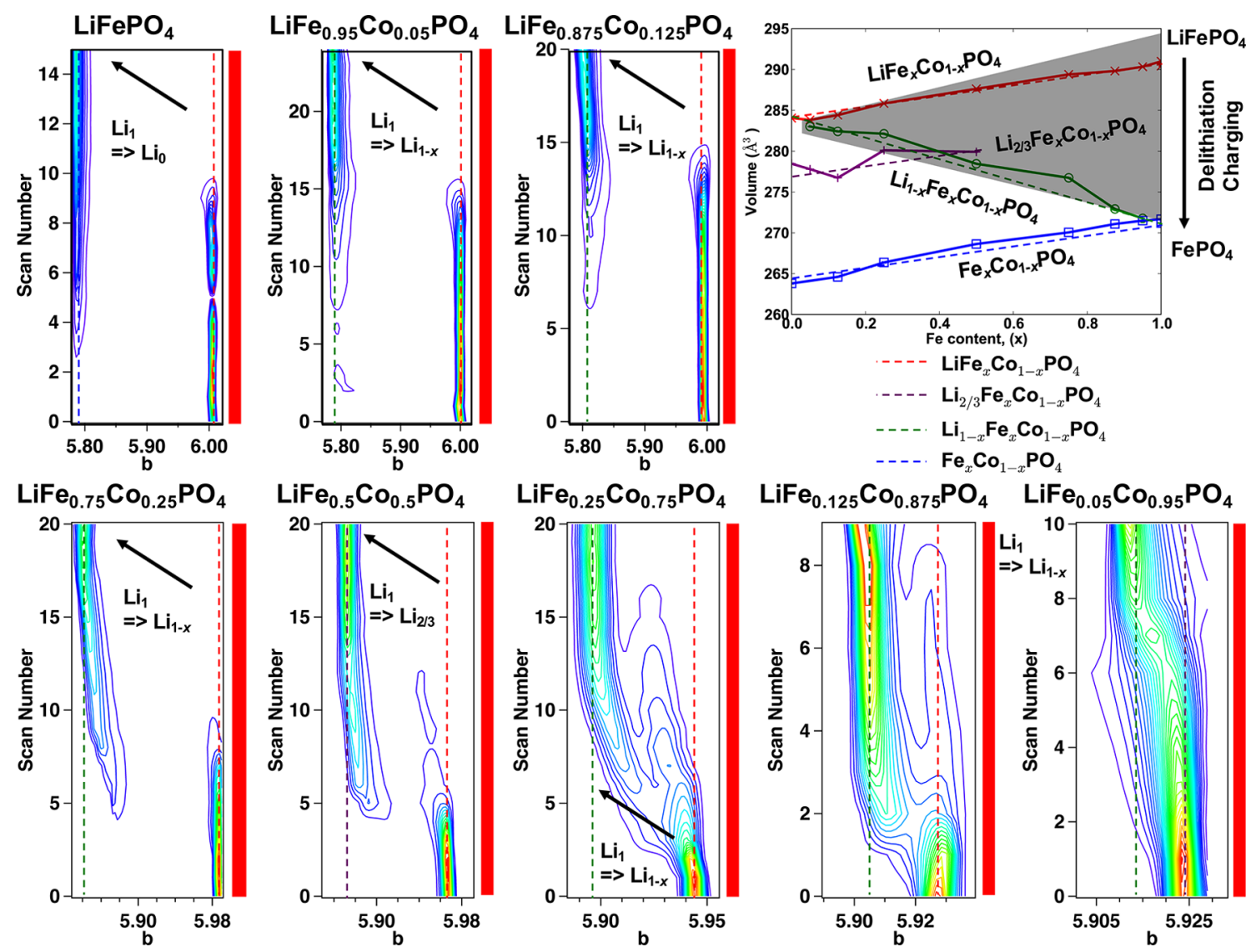

Figure 9. Variations in the $b$ lattice parameter, plotted as population density, as a function of the scan number for $\mathrm{LiFe}_{x} \mathrm{Co}_{1-x} \mathrm{PO}_{4}$ with $x=1,0.95,0.875$, $0.75,0.5,0.25,0.125$, and 0.05 . These were extracted from refinements using whole-powder-pattern fits. The plot at the top right shows the volume changes, and the gray-shaded area highlights those that occur when the fully lithiated phase is delithiated. The red bars alongside the plots indicate that it is the $\mathrm{Li}_{1} \mathrm{Fe}_{x} \mathrm{Co}_{1-x} \mathrm{PO}_{4}$ phase that is being consumed as the material is delithiated.

the end-member phases toward each other are more discernible, even in the first charge (Figure 9 for $\mathrm{LiFe}_{0.875} \mathrm{Co}_{0.125} \mathrm{PO}_{4}$ ).

The delithiation mechanisms for $\mathrm{LiFe}_{0.75} \mathrm{Co}_{0.25} \mathrm{PO}_{4}$ and $\mathrm{LiFe}_{0.5} \mathrm{Co}_{0.5} \mathrm{PO}_{4}$ at the onset of charge involve a bulk shift of the lattice parameters from those of the end members, $\mathrm{LiFe}_{x} \mathrm{Co}_{1-x} \mathrm{PO}_{4}$ and $\mathrm{Li}_{1-x} \mathrm{Fe}_{x} \mathrm{Co}_{1-x} \mathrm{PO}_{4}$, as well as an asymmetric broadening in the parameters toward each other. In section 3.3, we ascribed the behavior seen for the delithiation of $\mathrm{LiFe}_{0.25} \mathrm{Co}_{0.75} \mathrm{PO}_{4}$ to form $\mathrm{Li}_{0.75} \mathrm{Fe}_{0.25} \mathrm{Co}_{0.75} \mathrm{PO}_{4}$ to that of a two-phase reaction occurring in the presence of a coherent interface. Therefore, the behavior of $\mathrm{LiFe}_{0.75} \mathrm{Co}_{0.25} \mathrm{PO}_{4}$ and $\mathrm{LiFe}_{0.5} \mathrm{Co}_{0.5} \mathrm{PO}_{4}$ is likely to be intermediate between those of the $\mathrm{Fe}$-rich materials and $\mathrm{LiFe}_{0.25} \mathrm{Co}_{0.75} \mathrm{PO}_{4}$. We will discuss in more detail how these mechanisms are related in section 3.5.

$\mathrm{LiFe}_{0.05} \mathrm{Co}_{0.95} \mathrm{PO}_{4}$ reacts via a bulk single-phase mechanism (mechanism C) to form the $\mathrm{Li}_{0.95} \mathrm{Fe}_{0.05} \mathrm{Co}_{0.95} \mathrm{PO}_{4}$ intermediate, as shown by a continuous shift in the lattice parameters, whereas $\mathrm{LiFe}_{0.125} \mathrm{Co}_{0.875} \mathrm{PO}_{4}$ has more "two-phase"-like behavior, as shown by the coexistence of the $\mathrm{LiFe}_{0.125} \mathrm{Co}_{0.875} \mathrm{PO}_{4}$ and $\mathrm{Li}_{0.875} \mathrm{Fe}_{0.125} \mathrm{Co}_{0.875} \mathrm{PO}_{4}$ lattice parameters, with some shift in the parameters toward each other. As the Fe content decreases, two phenomena occur: the difference between the cell parameters of $\mathrm{LiFe}_{x} \mathrm{Co}_{1-x} \mathrm{PO}_{4}$ and $\mathrm{Li}_{1-x} \mathrm{Fe}_{x} \mathrm{Co}_{1-x} \mathrm{PO}_{4}$ decreases and the substitution levels (i.e., the disruption in the lattice) decrease. The former favors the single-phase mechanism (as observed for $\left.\mathrm{LiFe}_{0.05} \mathrm{Co}_{0.95} \mathrm{PO}_{4}\right)$ and the latter results in a shorter coherent interface (as the lattice has fewer dopant Fe particles, leading to reduced structural elasticity) in the two-phase reaction, as seen for $\mathrm{LiFe}_{0.125} \mathrm{Co}_{0.875} \mathrm{PO}_{4}$. These two competing phenomena must cause the apparent "break" in trend for $\mathrm{LiFe}_{0.125} \mathrm{Co}_{0.875} \mathrm{PO}_{4}$.

3.5. Discussion of How the Mechanisms Are Related and Interconvert. As demonstrated in section 3.4, there is not a sharp cutoff between the various mechanisms as the Co content increases. In Figure 10 we summarize how the mechanisms are interconnected. From previous studies ${ }^{3,6}$ of partially charged samples of $\mathrm{LiFePO}_{4}$, we know that as we increase the particle size, the two end-member phases (i.e., $\mathrm{FePO}_{4}$ and $\mathrm{LiFePO}_{4}$ ) are able to coexist within a particle rather than existing in separate particles (the transition from scheme $\mathbf{B}$ to scheme $\mathbf{A}$ in Figure 10).

We saw in section 3.2 that at low cycle rates, nanoparticulate $\mathrm{LiFePO}_{4}$ delithiates via the single-phase mechanism with few particles reacting at once (scheme $\mathbf{B}$ ). As the Co content increases in going from $\mathrm{LiFePO}_{4}$ to $\mathrm{LiFe}_{0.95} \mathrm{Co}_{0.05} \mathrm{PO}_{4}$ and $\mathrm{LiFe}_{0.875} \mathrm{Co}_{0.125} \mathrm{PO}_{4}$, more particles react simultaneously during delithiation of the fully lithiated phase on the plateau of the $\mathrm{Fe}^{2+} / \mathrm{Fe}^{3+}$ oxidation reaction, as demonstrated by the pathway from scheme $\mathbf{B}$ to scheme $\mathbf{D}$ in Figure 10. The studies by Liu et al. ${ }^{12}$ showed that as the current applied to the system increases, the same trend is observed (scheme $\mathbf{B}$ to scheme $\mathbf{D}$ ). A more pronounced effect (i.e., even more particles react simultaneously) is seen when forming the fully delithiated phase during the $\mathrm{Co}^{2+} / \mathrm{Co}^{3+}$ oxidation reaction for increasing $\mathrm{Fe}$ content, for $x=0.125,0.5,0.75$, and 0.875 (scheme $\mathbf{D}$ to scheme $\mathrm{C}$ ), eventually leading to the bulk single-phase mechanism (C) for the transformation between $\mathrm{Li}_{0.125} \mathrm{Fe}_{0.875} \mathrm{Co}_{0.125} \mathrm{PO}_{4}$ and $\mathrm{Fe}_{0.875} \mathrm{Co}_{0.125} \mathrm{PO}_{4}$. 


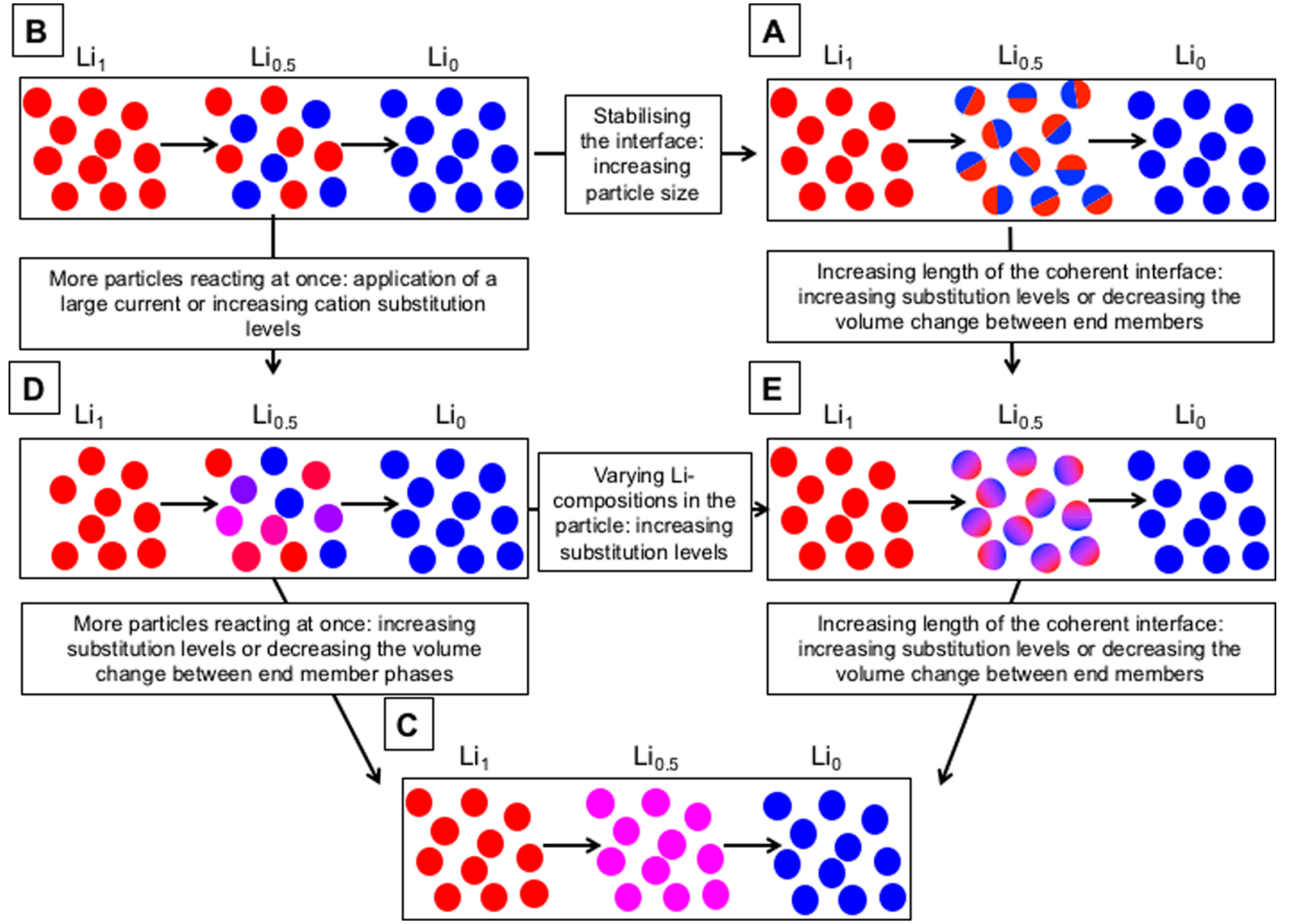

Figure 10. Schematic illustration showing how the apparently different delithiation mechanisms are interconnected. The lettering A-E corresponds to that introduced in Figure 1.

Using Figure 10, we are now able to better understand the trend in the mechanisms observed in Figure 9. We know that increasing the Co content in the substituted olivines increases the number of particles that react simultaneously during the plateau of the $\mathrm{Fe}^{2+} / \mathrm{Fe}^{3+}$ oxidation reaction (scheme $\mathbf{B} \rightarrow$ scheme $\mathbf{D}$ ), and we know that a two-phase mechanism containing a coherent interface is observed when $\mathrm{LiFe}_{0.25} \mathrm{Co}_{0.75} \mathrm{PO}_{4}$ is delithiated to form $\mathrm{Li}_{0.75} \mathrm{Fe}_{0.25} \mathrm{Co}_{0.75} \mathrm{PO}_{4}$ (scheme $\mathrm{E}$ ). Therefore, between $\mathrm{LiFe}_{0.75} \mathrm{Co}_{0.25} \mathrm{PO}_{4}$ and $\mathrm{LiFe}_{0.5} \mathrm{Co}_{0.5} \mathrm{PO}_{4}$, the mechanism is transitioning from $\mathbf{D}$ to $\mathbf{E}$ : both more particles are reacting at once and the intermediate lithium compositions are now able to coexist within a particle rather than between particles. As we further increase the Co content in going from $\mathrm{LiFe}_{0.25} \mathrm{Co}_{0.75} \mathrm{PO}_{4}$ to $\mathrm{LiFe}_{0.05} \mathrm{Co}_{0.95} \mathrm{PO}_{4}$, we move from scheme $\mathbf{E}$ to scheme $\mathbf{C}$ : the length of the coherent interface increases to the size of the particles (as demonstrated in our simulations in Figure 5). As explained in section 3.4.3, the apparent "anomaly" in the mechanisms for $\mathrm{LiFe}_{0.125} \mathrm{Co}_{0.875} \mathrm{PO}_{4}$ is due to opposing effects arising from the decrease in the change in volume during the reaction and the reduced coherency at the interface (owing to the decreasing amount of disorder resulting from reduced Co content). Therefore, even though it is possible to correlate the trends in the behavior in the mechanisms with changing substitution levels, because of the complicated interplay between lattice disruption and change in volume it is still not trivial to predict what mechanism will occur when. Nonetheless, studying the whole series has provided considerable insight into the general trends and dominant factors controlling the mechanism.

\section{CONCLUSIONS}

A comprehensive mechanistic study of the delithiation of the cosubstituted $\mathrm{LiFe}_{x} \mathrm{Co}_{1-x} \mathrm{PO}_{4}$ materials was performed using in situ XRD. Correlations between the seemingly different mechanisms have been discussed within the cosubstituted olivines (as summarized in Figure 11), the $\mathrm{LiFe}_{x} \mathrm{Co}_{1-x} \mathrm{PO}_{4}$ series $(0 \leq x \leq 0.95)$. They are distinguished by the length of the coherent interface and whether the intermediate Li compositions (i.e., those between the fully lithiated and fully delithiated values) coexist within or between the particles. Increasing the Co substitution level increases the number of observable particles reacting via the single-phase mechanism during the plateau of the $\mathrm{Fe}^{2+} / \mathrm{Fe}^{3+}$ oxidation reaction and vice versa (i.e., Fe substitution increases the observable number of particles reacting via the single-phase mechanism during the $\mathrm{Co}^{2+} / \mathrm{Co}^{3+}$ oxidation reaction). From previous studies, ${ }^{12}$ we know that this is also the case when a larger current is applied. Increasing the substitution levels also allows intermediate $\mathrm{Li}$ compositions to exist within the particle rather than between particles (i.e., the coherent interface). It was also observed that the difference between the volumes of the two species in each transformation is important and that when there is a small difference in volume the single-phase reaction is likely to occur.

This study helps to establish how the solid solution mechanisms are related to the two-phase mechanism, how the mechanisms are affected by the varying length of the coherent interface, and how the different mechanisms can be distinguished using in situ XRD. It is key to understand how the battery electrode materials lithiate and delithiate in order to optimize current materials and provide a foundation for what characteristics future cathode materials should have (i.e., dopant and substituted materials). Critically, the formation of interfaces versus solid solutions during structural transformations can have implications for the fracturing of particles over multiple cycles: no energetically unfavorable interfaces are formed 


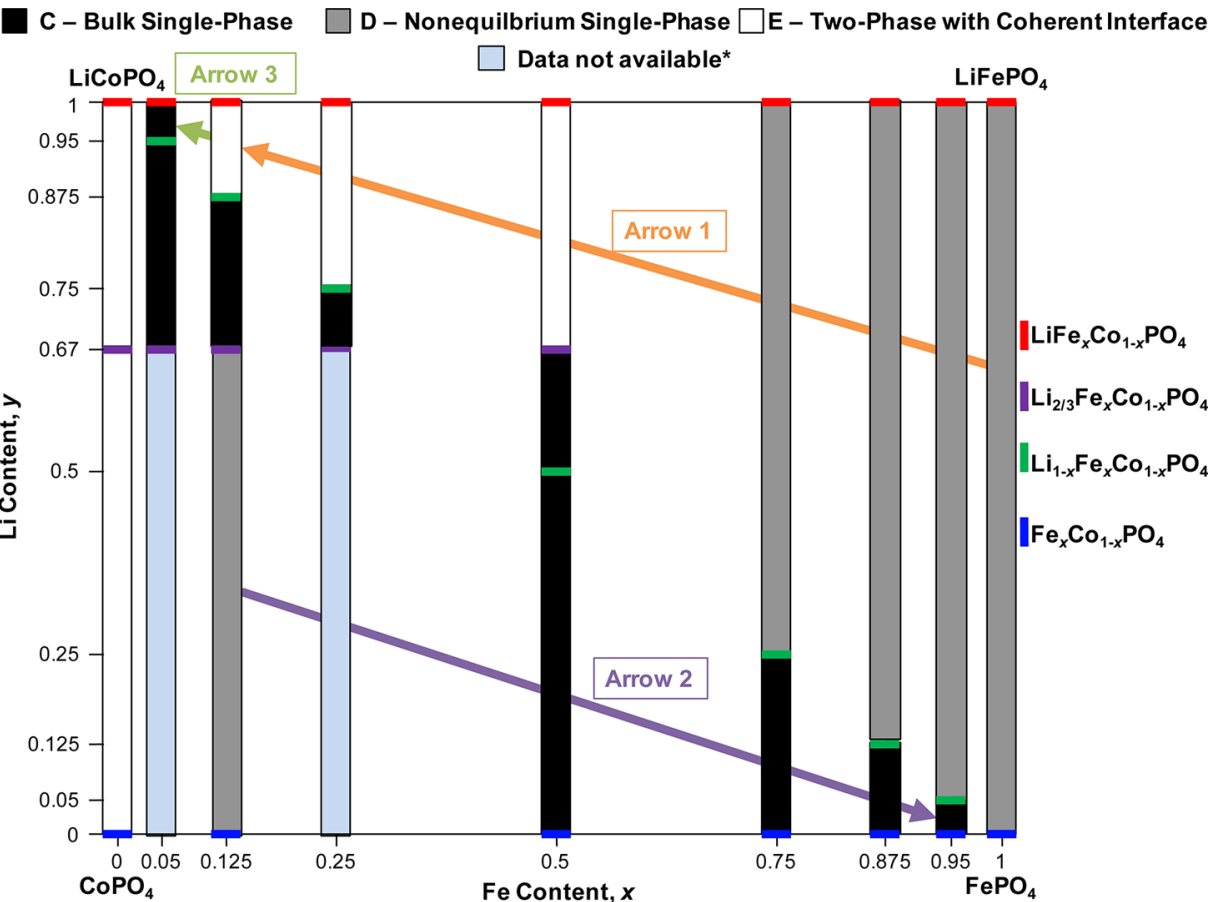

Figure 11. Pseudophase diagram of $\mathrm{Li}_{y} \mathrm{Fe}_{x} \mathrm{Co}_{1-x} \mathrm{PO}_{4}$ showing the evolution of the phases and the mechanisms by which they delithiate with decreasing $\mathrm{Li}$ content and varying Fe content $(0 \leq x, y \leq 1)$. Red, green, purple, and blue represent the $\mathrm{Li}_{1^{-}}, \mathrm{Li}_{1-x^{-}}, \mathrm{Li}_{2 / 3^{-}}$, and $\mathrm{Li}_{0} \mathrm{Fe}_{x} \mathrm{Co}_{1-x} \mathrm{PO}_{4}$ phases, respectively, and the black, gray, and white bars represent the bulk single-phase mechanism $(\mathbf{C})$, the nonequilbrium single-phase mechanism occurring particle-by-particle (D), and the two-phase mechanism with a coherent interface (E), respectively. Arrow 1 shows varying Li compositions existing within rather than between the particles (scheme $\mathbf{D}$ to scheme $\mathbf{E}$ ). The direction of arrow 1 shows the change of the mechanism from the single-phase transition occurring discretely between particles to the two-phase mechanism with significant coherency at the interface. The direction of arrow 2 indicates an increase in the number of particles reacting simultaneously (scheme $\mathbf{D}$ to scheme $\mathbf{C}$ ). Arrow 3 shows an increasing length of the coherent interface, i.e., a transition from scheme $\mathbf{E}$ to scheme $\mathrm{D}$. *The end of charge for $\mathrm{LiFe}_{0.05} \mathrm{Co}_{0.95} \mathrm{PO}_{4}$ was not collected because of limitations at the beamline, and the fully delithiated phase was not observed on the first charge for $\mathrm{LiFe}_{0.25} \mathrm{Co}_{0.75} \mathrm{PO}_{4}$.

for a solid solution, leading to improved capacity retention. Furthermore, solid-solution mechanisms should in general lead to higher-rate materials and improved performance.

\section{ASSOCIATED CONTENT}

\section{S Supporting Information}

The Supporting Information is available free of charge on the ACS Publications website at DOI: 10.1021/acs.chemmater.6b00319.

The electrochemistry recorded during the in situ XRD experiments and the points in the electrochemistry at which the diffraction patterns were collected; three individual in situ XRD patterns, Rietveld refinements, and difference plots of $\mathrm{LiFePO}_{4}$ at different states of charge; XRD patterns of $\mathrm{LiFe}_{x} \mathrm{Co}_{1-x} \mathrm{PO}_{4}(0 \leq x \leq 1)$; SEM image of $\mathrm{LiFePO}_{4}$ composite electrode and particle size analysis and SEM images of as-synthesized $\mathrm{LiCoPO}_{4}$; discharge capacities obtained during the in situ XRD studies; electrochemical data collected during the in situ XRD experiments; ex situ ${ }^{31} \mathrm{P}$ NMR spectra at the end of the first charge for $\mathrm{LiFe}_{x} \mathrm{Co}_{1-x} \mathrm{PO}_{4}(0 \leq x \leq 1)$; individual XRD patterns at different states of charge for the Fe-rich materials $(x=1,0.95,0.875)$; evidence for the formation of the fully delithiated $\mathrm{Fe}_{0.25} \mathrm{Co}_{0.75} \mathrm{PO}_{4}$ phase at the end of the second charge; concentration profile along the $a$ axis of the $100 \mathrm{~nm}$ particle used in the simulation; XRD patterns for the first charge; the $a, b$, and $c$ unit cell parameters for $\mathrm{LiFe}_{x} \mathrm{Co}_{1-x} \mathrm{PO}_{4}, \mathrm{Fe}_{x} \mathrm{Co}_{1-x} \mathrm{PO}_{4}, \mathrm{Li}_{1-x} \mathrm{Fe}_{x} \mathrm{Co}_{1-x} \mathrm{PO}_{4}$, and $\mathrm{Li}_{2 / 3} \mathrm{Fe}_{x} \mathrm{Co}_{1-x} \mathrm{PO}_{4}(0 \leq x \leq 1)$ as functions of Fe content; percentage change in the lattice parameters compared with $\mathrm{LiFePO}_{4}$ for $\mathrm{LiFe}_{x} \mathrm{Co}_{1-x} \mathrm{PO}_{4}, \mathrm{Fe}_{x} \mathrm{Co}_{1-x} \mathrm{PO}_{4}$ $\mathrm{Li}_{1-x} \mathrm{Fe}_{x} \mathrm{Co}_{1-x} \mathrm{PO}_{4}$, and $\mathrm{Li}_{2 / 3} \mathrm{Fe}_{x} \mathrm{Co}_{1-x} \mathrm{PO}_{4}(0 \leq x \leq 1)$ and the $a, b$, and $c$ lattice parameter variations, plotted as populations densities, as functions of scan number for all of the reactions discussed in this paper (PDF)

\section{AUTHOR INFORMATION}

\section{Corresponding Author}

*E-mail: cpg27@cam.ac.uk.

\section{Present Addresses}

"H.L.: X-ray Science Division, Advanced Photon Source, Argonne National Laboratory, Argonne, Illinois 60439, USA.

${ }^{\perp}$ M.L.: Weizmann Institute of Science, Rehovot 76100, Israel.

\section{Notes}

The authors declare no competing financial interest.

All the raw data for the XRD can be accessed from the University of Cambridge data repository available at the following DOI link: http://dx.doi.org/10.17863/CAM.21.

\section{ACKNOWLEDGMENTS}

We thank the EPSRC for a Doctoral Training Partnership Award and the Department of Energy for support via the NorthEast Center for Chemical Energy Storage, an Energy Frontier Research Center funded by the U.S. Department of Energy, Office of Science, Office of Basic Energy Sciences under Award DE-SC0012583 (support to F.C.S.). We thank the EU for funding from European FP7-265368 via the Eurolion Project and the Cambridge Overseas Trust (H.L.) and a Marie Curie 
Intra-European Fellowship (M.L.). Work done at Argonne and use of the Advanced Photon Source (APS), an Office of Science User Facility operated for the U.S. Department of Energy Office of Science by Argonne National Laboratory, were supported by the U.S. Department of Energy under Contract DE-AC0206CH11357. We thank Tao Liu for help with SEM; Dr. Xiao Hua, Ieuan Seymour, Dr. Phoebe Allan, and Dr. Sylvia Britto for their help and discussions; Dr. Matthew Suchomel for instrument support; and Dr. Jan Ilavsky for help with the Irena software.

\section{REFERENCES}

(1) Padhi, A. K.; Nanjundaswamy, K. S.; Goodenough, J. B. Phosphoolivines as Positive-Electrode Materials for Rechargeable Lithium Batteries. J. Electrochem. Soc. 1997, 144, 1188-1194.

(2) Yonemura, M.; Yamada, A.; Takei, Y.; Sonoyama, N.; Kanno, R. Comparative Kinetic Study of Olivine $\mathrm{LiMPO}_{4}(\mathrm{M}=\mathrm{Fe}, \mathrm{Mn})$. J. Electrochem. Soc. 2004, 151, A1352-A1356.

(3) Chen, G.; Song, X.; Richardson, T. J. Electron Microscopy Study of the $\mathrm{LiFePO}_{4}$ to $\mathrm{FePO}_{4}$ Phase Transition. Electrochem. Solid-State Lett. 2006, 9, A295-A298.

(4) Morgan, D.; Van der Ven, A.; Ceder, G. Li Conductivity in $\mathrm{Li}_{x} \mathrm{MPO}_{4}(\mathrm{M}=\mathrm{Mn}, \mathrm{Fe}, \mathrm{Co}, \mathrm{Ni})$ Olivine Materials. Electrochem. SolidState Lett. 2004, 7, A30-A32.

(5) Malik, R.; Burch, D.; Bazant, M.; Ceder, G. Particle Size Dependence of the Ionic Diffusivity. Nano Lett. 2010, 10, 4123-4127.

(6) Delmas, C.; Maccario, M.; Croguennec, L.; Le Cras, F.; Weill, F. Lithium deintercalation in $\mathrm{LiFePO}_{4}$ nanoparticles via a domino-cascade model. Nat. Mater. 2008, 7, 665-671.

(7) Yu, Y.-S.; Kim, C.; Shapiro, D. A.; Farmand, M.; Qian, D.; Tyliszczak, T.; Kilcoyne, A. L. D.; Celestre, R.; Marchesini, S.; Joseph, J.; Denes, P.; Warwick, T.; Strobridge, F. C.; Grey, C. P.; Padmore, H.; Meng, Y. S.; Kostecki, R.; Cabana, J. Dependence on Crystal Size of the Nanoscale Chemical Phase Distribution and Fracture in $\mathrm{Li}_{x} \mathrm{FePO}_{4}$. Nano Lett. 2015, 15, 4282-4288.

(8) Kang, B.; Ceder, G. Battery materials for ultrafast charging and discharging. Nature 2009, 458, 190-193.

(9) Lee, K. T.; Kan, W. H.; Nazar, L. F. Proof of Intercrystallite Ionic Transport in $\mathrm{LiMPO}_{4}$ Electrodes $(\mathrm{M}=\mathrm{Fe}, \mathrm{Mn})$. J. Am. Chem. Soc. 2009, 131, 6044-6045.

(10) Malik, R.; Zhou, F.; Ceder, G. Kinetics of non-equilibrium lithium incorporation in $\mathrm{LiFePO}_{4}$. Nat. Mater. 2011, 10, 587-590.

(11) Ferguson, T. R.; Bazant, M. Z. Nonequilibrium Thermodynamics of Porous Electrodes. J. Electrochem. Soc. 2012, 159, A1967-A1985.

(12) Liu, H.; Strobridge, F. C.; Borkiewicz, O. J.; Wiaderek, K. M.; Chapman, K. W.; Chupas, P. J.; Grey, C. P. Capturing metastable structures during high-rate cycling of $\mathrm{LiFePO}_{4}$ nanoparticle electrodes. Science 2014, 344, 1252817.

(13) Zhang, X.; van Hulzen, M.; Singh, D. P.; Brownrigg, A.; Wright, J. P.; van Dijk, N. H.; Wagemaker, M. Rate-Induced Solubility and Suppression of the First-Order Phase Transition in Olivine $\mathrm{LiFePO}_{4}$. Nano Lett. 2014, 14, 2279-2285.

(14) Ravnsbæk, D. B.; Xiang, K.; Xing, W.; Borkiewicz, O. J.; Wiaderek, K. M.; Gionet, P.; Chapman, K. W.; Chupas, P. J.; Chiang, Y.-M. Extended Solid Solutions and Coherent Transformations in Nanoscale Olivine Cathodes. Nano Lett. 2014, 14, 1484-1491.

(15) Zhang, X.; van Hulzen, M.; Singh, D. P.; Brownrigg, A.; Wright, J. P.; van Dijk, N. H.; Wagemaker, M. Direct view on the phase evolution in individual $\mathrm{LiFePO} 4$ nanoparticles during Li-ion battery cycling. Nat. Commun. 2015, 6, 8333.

(16) Shin, H. C.; Park, S. B.; Jang, H.; Chung, K. Y.; Cho, W. I.; Kim, C. S.; Cho, B. W. Rate performance and structural change of Cr-doped $\mathrm{LiFePO}_{4} / \mathrm{C}$ during cycling. Electrochim. Acta 2008, 53, 7946-7951.

(17) Bramnik, N. N.; Trots, D. M.; Hofmann, H. J.; Ehrenberg, H. Mixed $\mathrm{LiCo}_{0.6} \mathrm{M}_{0.4} \mathrm{PO}_{4}(\mathrm{M}=\mathrm{Mn}, \mathrm{Fe}, \mathrm{Ni})$ phosphates: cycling mechanism and thermal stability. Phys. Chem. Chem. Phys. 2009, 11, 3271-3277.
(18) Omenya, F.; Chernova, N. A.; Zhang, R.; Fang, J.; Huang, Y.; Cohen, F.; Dobrzynski, N.; Senanayake, S.; Xu, W.; Whittingham, M. S. Why Substitution Enhances the Reactivity of $\mathrm{LiFePO}_{4}$. Chem. Mater. 2013, 25, 85-89.

(19) Park, K. Y.; Hong, J.; Kim, J.; Park, Y. U.; Kim, H.; Seo, D. H.; Kim, S. W.; Choi, J. W.; Kang, K. Factors that Affect the Phase Behavior of Multi-Component Olivine $\left(\mathrm{LiFe}_{x} \mathrm{Mn}_{y} \mathrm{Co}_{1-x-y} \mathrm{PO}_{4} ; 0<x, y<1\right)$ in Lithium Rechargeable Batteries: One-Phase Reaction vs. Two-Phase Reaction. J. Electrochem. Soc. 2013, 160, A444-A448.

(20) Hong, J.; Wang, C. S.; Chen, X.; Upreti, S.; Whittingham, M. S. Vanadium Modified $\mathrm{LiFePO}_{4}$ Cathode for Li-Ion Batteries. Electrochem. Solid-State Lett. 2009, 12, A33-A38.

(21) Bramnik, N. N.; Nikolowski, K.; Baehtz, C.; Bramnik, K. G.; Ehrenberg, H. Phase Transitions Occurring upon Lithium InsertionExtraction of $\mathrm{LiCoPO}_{4}$. Chem. Mater. 2007, 19, 908-915.

(22) Ehrenberg, H.; Bramnik, N. N.; Senyshyn, A.; Fuess, H. Crystal and magnetic structures of electrochemically delithiated $\mathrm{Li}_{1-x} \mathrm{CoPO}_{4}$ phases. Solid State Sci. 2009, 11, 18-23.

(23) Bramnik, N. N.; Bramnik, K. G.; Baehtz, C.; Ehrenberg, H. Study of the effect of different synthesis routes on Li extraction-insertion from $\mathrm{LiCoPO}_{4}$. J. Power Sources 2005, 145, 74-81.

(24) Strobridge, F. C.; Clément, R. J.; Leskes, M.; Middlemiss, D. S.; Borkiewicz, O.J.; Wiaderek, K. M.; Chapman, K. W.; Chupas, P.J.; Grey, C. P. Identifying the Structure of the Intermediate, $\mathrm{Li}_{2 / 3} \mathrm{CoPO}_{4}$, Formed during Electrochemical Cycling o $\mathrm{LiCoPO}_{4}$. Chem. Mater. 2014, 26, 6193-6205.

(25) Kobayashi, G.; Nishimura, S.-I.; Park, M.-S.; Kanno, R.; Yashima, M.; Ida, T.; Yamada, A. Isolation of Solid Solution Phases in SizeControlled $\mathrm{Li}_{x} \mathrm{FePO}_{4}$ at Room Temperature. Adv. Funct. Mater. 2009, $19,395-403$.

(26) Borkiewicz, O. J.; Shyam, B.; Wiaderek, K. M.; Kurtz, C.; Chupas, P. J.; Chapman, K. W. The AMPIX electrochemical cell: a versatile apparatus for in situ X-ray scattering and spectroscopic measurements. J. Appl. Crystallogr. 2012, 45, 1261-1269.

(27) Lee, P. L.; Shu, D.; Ramanathan, M.; Preissner, C.; Wang, J.; Beno, M. A.; Von Dreele, R. B.; Ribaud, L.; Kurtz, C.; Antao, S. M.; Jiao, X.; Toby, B. H. A twelve-analyzer detector system for high-resolution powder diffraction. J. Synchrotron Radiat. 2008, 15, 427-432.

(28) Stinton, G. W.; Evans, J. S. O. Parametric Rietveld refinement. J. Appl. Crystallogr. 2007, 40, 87-95.

(29) Jarvinen, M. Application of Symmetrized Harmonics Expansion to Correction of the Preferred Orientation Effect. J. Appl. Crystallogr. 1993, 26, 525-531.

(30) Popa, N. C. Texture in Rietveld Refinement. J. Appl. Crystallogr. 1992, 25, 611-616.

(31) Coelho, A. A. A charge-flipping algorithm incorporating the tangent formula for solving difficult structures. Acta Crystallogr., Sect. A: Found. Crystallogr. 2007, 63, 400-406.

(32) Warren, B. E. X-ray Diffraction; Addison-Wesley: Reading, MA, 1969.

(33) Rudman, P. S. An X-ray Diffraction Method for the Determination of Composition Distribution in Inhomogeneous Binary Solid Solution. Acta Crystallogr. 1960, 13, 905-909.

(34) Kang, H.-C.; Jun, D.-K.; Jin, B.; Jin, E. M.; Park, K.-H.; Gu, H.-B.; Kim, K.-W. Optimized solid-state synthesis of $\mathrm{LiFePO}_{4}$ cathode materials using ball-milling. J. Power Sources 2008, 179, 340-346.

(35) Yang, X.; Liu, D.; Xu, X.; He, X.; Xie, J. Mechanism and kinetic studies on the synthesis of $\mathrm{LiFePO}_{4}$ via solid-state reactions. CrystEngComm 2013, 15, 10648-10656.

(36) Tarascon, J. M.; Guyomard, D. New electrolyte compositions stable over the 0 to $5 \mathrm{~V}$ voltage range and compatible with the $\mathrm{Li}_{1+x} \mathrm{Mn}_{2} \mathrm{O}_{4} /$ carbon Li-ion cells. Solid State Ionics 1994, 69, 293-305.

(37) Guyomard, D.; Tarascon, J. M. High voltage stable liquid electrolytes for $\mathrm{Li}_{1+x} \mathrm{Mn}_{2} \mathrm{O}_{4}$ /carbon rocking-chair lithium batteries. J. Power Sources 1995, 54, 92-98.

(38) Snook, G. A.; Huynh, T. D.; Hollenkamp, A. F.; Best, A. S. Rapid SECM probing of dissolution of $\mathrm{LiCoO}_{2}$ battery materials in an ionic liquid. J. Electroanal. Chem. 2012, 687, 30-34. 
(39) Bai, P.; Cogswell, D. A.; Bazant, M. Z. Suppression of Phase Separation in $\mathrm{LiFePO}_{4}$ Nanoparticles During Battery Discharge/. Nano Lett. 2011, 11, 4890-4896.

(40) Meethong, N.; Huang, H.-Y. S.; Carter, W. C.; Chiang, Y.-M. SizeDependent Lithium Miscibility Gap in Nanoscale $\mathrm{Li}_{1-x} \mathrm{FePO}_{4}$. Electrochem. Solid-State Lett. 2007, 10, A134-A138.

(41) Molenda, J.; Kulka, A.; Milewska, A.; Zając, W.; Świerczek, K. Structural, Transport and Electrochemical Properties of $\mathrm{LiFePO}_{4}$ Substituted in Lithium and Iron Sublattices (Al, Zr, W, Mn, Co and $\mathrm{Ni})$. Materials 2013, 6, 1656-1687.

(42) Nytén, A.; Thomas, J. O. A neutron powder diffraction study of $\mathrm{LiCo}_{x} \mathrm{Fe}_{1-x} \mathrm{PO}_{4}$ for $x=0,0.25,0.40,0.60$ and 0.75 . Solid State Ionics 2006, $177,1327-1330$.

(43) Shannon, R. D. Revised Effective Ionic Radii and Systematic Studies of Interatomic Distances in Halides and Chalcogenides. Acta Crystallogr., Sect. A: Cryst. Phys., Diffr., Theor. Gen. Crystallogr. 1976, 32, 751-767. 